\title{
ECONOMC ANALYSIS
}

WORKING PAPER SERIES

Return to Dollar, Generalized Distance Function and the Fisher Productivity Index

\author{
J osé L. Zofío and Angel M Prieto
}

Working Paper 1/2005

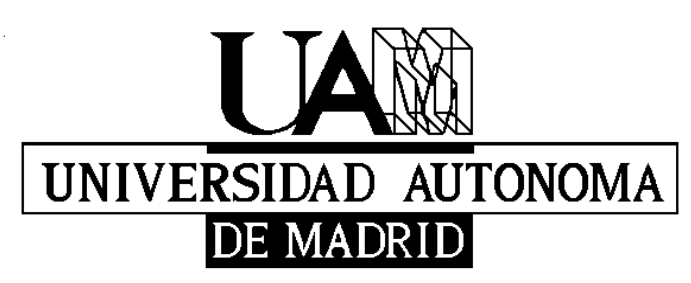

\section{DEPARTAMENTO DE ANÁLISSS ECONÓMCO: TEORÍA ECONÓMCA E HISTORIA ECONÓMCA}




\title{
Return to Dollar, Generalized Distance Function and the Fisher Productivity Index
}

\author{
José L. Zofío ${ }^{\mathrm{a},}{ }^{*}$ and Angel M. Prieto ${ }^{\mathrm{b}}$ \\ ${ }^{a}$ Departamento de Análisis Económico: Teoría Económica e Historia Económica. \\ Universidad Autónoma de Madrid, E-28049 Cantoblanco, Madrid, Spain. \\ ${ }^{\mathrm{b}}$ Ministerio de Educación y Ciencia - C.S.I.C. , Cordel de Merinas 40-52, E-37008 \\ Salamanca, Spain.
}

October 1,2005

\begin{abstract}
Exploring the duality between a return to dollar definition of profit and the generalized distance function we establish the relationship between the Laspeyres, Paasche and Fisher productivity indexes and their alternative Malmquist indexes counterparts. By proceeding this way, we propose a consistent decomposition of these productivity indexes into two mutually exclusive components. A technical component represented by the Malmquist index and an economical component which can be identified with the contribution that allocative criteria make to productivity change. With regard to the Fisher index, we indicate how researchers can further decompose the Malmquist technical component rendering explicit the sources of productivity change. We also show how the proposed model can be implemented by means of Data Envelopment Analysis techniques, and illustrate the empirical process with an example data set.
\end{abstract}

Key Words: Generalized Distance Function, Return to Dollar, Fisher and Malmquist Productivity Indexes.

JEL Classification: C43, C61, D24.

\footnotetext{
${ }^{a}$ Corresponding author. Tel: +34 914972406; fax: +34 914978616; e-mail: jose.zofio@uam.es

b Tel: +34 923219606; fax: +34 923219609; e-mail: alpiste@usal.es.

* We appreciate the contributions of Bert Balk and Luis Orea throughout the development of this manuscript. We are also grateful to two anonymous reviewers for their helpful comments that greatly improved the finished work. The usual disclaimer applies.
} 


\section{Introduction}

In the last decade a renewed interest in productivity analysis has emerged, placing this issue in the front row of academic research programs and statistical offices' systematic operations. However, while academics are mainly focused on issues that put a premium on theoretical and estimation issues when producing scientific output, statisticians are mainly concerned with simplicity and reliability when releasing regular data and time series. This paper contributes to the literature that intends to bridge the gap between these two complementary working groups, by extracting from current academic research the knowledge that can support and ease the practical implementation of regular productivity statistics, which can better inform about the relevant sources of productivity change

In its recent Measuring Productivity manual, the Organization for Economic Co-operation and Development sets a landmark in applied productivity analysis by showing, in a comprehensive way, the existing alternatives to measure the residual that is known since Abramovitz (1958) as the "measure of our ignorance" (OECD, 2001). In this manual, the OECD clearly advocates for the implementation of non-parametric methods of productivity measurement because (i) its primary audience are statistical offices and other regular producers of productivity series and (ii) they can be much more easily implemented and updated than their econometric counterparts. As expected, the OECD adopts the widely known definition of productivity as a ratio of a volume measure of outputs to a volume measure of inputs, which can be extended into a dynamic context by considering how this ratio changes in time. The fact that we are dealing with volumes of output and inputs implicitly calls for productivity measures that are suited for multiple output-multiple input technologies. In this context, the purpose of any productivity analysis is to reduce "the measure of our ignorance" as much as possible, thus identifying the relevant sources that explain differences in productivity levels among production processes in an industry, as well as productivity change.

Among these sources, the OECD signals out the ability to characterize the production technology, productive efficiency -which in turns requires determination of the benchmark production processes- and real cost savings -see OECD (2001:8). Here, the technology is seen as the "currently known ways of converting resources into outputs desired by the economy" (Griliches, 1987); productive efficiency corresponds to the 
concept introduced by Farrell (1957), i.e. the ability to produce "the maximum amount of output that is physically achievable with current technology" (Diewert and Lawrence, 1999) and, following Harberger (1998), real cost savings may be interpreted as an allocative efficiency measure that links all the above technical and efficiency factors with an economic measure of performance. In this paper we redefine this author's economic criterion to evaluate economic performance by substituting real cost savings in production (an idea linked to cost minimization) with its equivalent Georgescu-Roegen's (1951) return to dollar function, who introduced as economic criterion to evaluate performance the ability of producers to attain maximum revenue to cost.

All these issues must be taken into account by statistical offices when choosing and implementing productivity measures. Because of its simplicity and reliability, standard practice in OECD member countries involves the use of non-parametric methods. In fact, making use of the existing exact and superlative index numbers literature, statistical offices do not normally go beyond calculation of the Fisher (1921) or the Törnqvist (1936) indexes, as they satisfy important axiomatic tests and economic properties that strongly justify their use in applied analysis -see Diewert (1992). However, how can we unveil what is behind these aggregates? How could we decompose these indexes into aggregates that inform us about the technology, efficiency and economic performance in a given industry? How can we undertake productivity analyses that fulfill the above requirements with regard to the identification of the role of technology, efficiency and economic factors in productivity differentials and productivity change?

In this article, we extend the duality theory summarized in Färe and Primont (1995) -partially retaken by Färe et al. (2002), to derive the dual return to dollar interpretation of the generalized graph distance function recently introduced by Chavas and Cox (1999). While these authors rely on the partially oriented output, input or specific hyperbolic distance functions when establishing the duality to revenue, cost and return to dollar, we make use of the flexible generalized distance function to establish a common framework for duality analysis that includes these preceding results as particular cases. Thanks to this analytical framework that extends and generalizes many partial contributions dispersedly found in the literature, we demonstrate how it is possible to decompose the Laspeyres (1871), Paasche (1874) and Fisher indexes into several components which correspond to the above mentioned technological, efficiency and economic factors. Specifically, we establish the relationship between these indexes and their equivalent Malmquist (1953) 
productivity indexes when the technology is characterized by the generalized distance function and a maximizing return to dollar economic behavior is assumed -an idea firstly proposed by Althin et al. (1996) who relied on the input distance function. In this context, we also show that the Laspeyres, Paasche, and Fisher indexes can be decomposed into technical and economic components if allocative inefficiency is allowed, i.e. using Mahler's inequality it is possible to approximate these index numbers by way of Malmquist indexes which are enhanced with a residual term that represents allocative criteria. Additionally, in the case of the Fisher index, we turn to the existing Malmquist productivity index decomposition literature to further decompose this technological component into technical change, technical efficiency change and the contribution that returns to scale make to productivity change. This last step provides a comprehensive way to jointly analyze efficiency and productivity change, thus connecting into a single framework the existing literature on return to dollar index numbers and productivity change decompositions.

The paper proceeds as follows. In the next section we define the generalized graph distance function, which completely characterizes the production technology, and discuss how it relates to its output, input and hyperbolic counterparts. In section 3 we show the duality between the generalized distance function and the return to dollar function, which is employed in section 4 to support a consistent interpretation of efficiency and productivity measurement. Section 5 extends the analysis to a dynamic context, showing that the Laspeyres, Paasche and Fisher indexes are equivalent to alternative Malmquist indexes, thus the role of technology and efficiency in productivity change can be identified. Also, in this section we show that in the presence of allocative inefficiency, productivity change can be consistently decomposed into an additional term which takes into account return to dollar economic criteria. In the sixth section we develop the Data Envelopment Analysis techniques necessary to calculate the generalized distance function and to implement the efficiency and productivity change model in the presence of multiple variables, showing its potential in empirical analysis. Section 7 illustrates the model using a simple example data set, and section 8 concludes. 


\section{The generalized graph distance function}

In this section we characterize the technology by way of the generalized graph distance function and show how it relates to its hyperbolic and partially oriented output and input counterparts. Let us consider a panel of $i=1, \ldots, \mathrm{I}$ processes observed in $t=1, \ldots, \mathrm{T}$ periods, transforming input vectors $x_{i}^{t}=\left(\mathrm{x}_{1 i}{ }^{t}, \ldots, \mathrm{x}_{\mathrm{N} i}{ }^{t}\right) \in \mathfrak{R}_{+}^{\mathrm{N}}$ into output vectors $y_{i}^{t}=\left(\mathrm{y}_{1 i}{ }^{t}, \ldots, \mathrm{y}_{\mathrm{M} i}{ }^{t}\right) \in$ $\mathfrak{R}_{+}^{\mathrm{M}}$. The technology can be represented by the production possibility set:

$\mathrm{T}^{t}=\{(x, y): x$ can produce $y$ at time $t\}$,

and we assume the standard axioms found in Färe and Primont (1995). This production structure can be expressed in equivalent terms through the input and output correspondences, $y \rightarrow \mathrm{L}^{t}\left(y, \mathrm{~T}^{t}\right) \subseteq \mathfrak{R}_{+}^{\mathrm{N}}$ and $x \rightarrow \mathrm{P}^{t}\left(x, \mathrm{~T}^{t}\right) \subseteq \mathfrak{R}_{+}^{\mathrm{M}}$, which respectively represent the set of all input vectors which yield $y$ and the set of all output vectors obtainable from $x$. These input and output correspondences are inferred from the graph production possibility set (1): $\mathrm{L}^{t}\left(y, \mathrm{~T}^{t}\right)=$ $\left\{x:(x, y) \in \mathrm{T}^{t}\right\}$ and $\mathrm{P}^{t}\left(x, \mathrm{~T}^{t}\right)=\left\{y:(x, y) \in \mathrm{T}^{t}\right\}$, while the graph can be also inferred from the input and output correspondences, $\mathrm{T}^{t}=\left\{(x, y) \in \mathfrak{R}_{+}^{\mathrm{N}+\mathrm{M}}: x \in \mathrm{L}^{t}\left(y, \mathrm{~T}^{t}\right), y \in \mathfrak{R}_{+}^{\mathrm{M}}\right\}=\left\{(x, y) \in \mathfrak{R}_{+}^{\mathrm{N}+\mathrm{M}}: y\right.$ $\left.\in \mathrm{P}^{t}\left(x, \mathrm{~T}^{t}\right), x \in \mathfrak{R}_{+}^{\mathrm{N}}\right\}$.

It is possible to define the generalized distance function in terms of $\mathrm{T}^{t}$ as the maximum expansion of the outputs vector and reduction of the inputs vector:

$$
\mathrm{D}_{\mathrm{G}}^{t}(x, y, \alpha)=\min \left\{\delta>0:\left(x \delta^{1-\alpha}, y / \delta^{\alpha}\right) \in \mathrm{T}^{t}\right\}, \quad x \in \mathfrak{R}_{+}^{\mathrm{N}}, y \in \mathfrak{R}_{+}^{\mathrm{M}}
$$

where $0 \leq \alpha \leq 1$ represents the relative weight that the distance function places on outputs and inputs when moving toward Isoq $T^{t}-$ a balanced weight is given by $\alpha=0.5$ as $\alpha /(1-\alpha)=$ 1. The generalized distance function (2) places a production process on the best practice frontier represented by the boundary of the technology-defined as $\operatorname{IsoqT}^{t}=\{(x, y):(x, y) \in$ $\left.\mathrm{T}^{t},\left(\omega^{1-\beta} x, y / \omega^{\beta}\right) \notin \mathrm{T}^{t}, 0<\omega<1,0 \leq \beta \leq 1\right\}$, and can be interpreted as a measure of technical efficiency in the sense of Farrell (1957). If the technology satisfies the standard axioms, then the generalized distance function verifies the following properties (Chavas and Cox, 1999: 300):

$\mathrm{D}_{\mathrm{G}} \cdot 1 \mathrm{D}_{\mathrm{G}}^{t}\left(\lambda^{\alpha-1} x, \lambda^{\alpha} y ; \alpha\right)=\lambda \mathrm{D}_{\mathrm{G}}^{t}(x, y ; \alpha), \lambda>0$, 
$\mathrm{D}_{\mathrm{G}} \cdot 2 \mathrm{D}_{\mathrm{G}}^{t}(x, \lambda y ; \alpha) \leq \mathrm{D}_{\mathrm{G}}^{t}(x, y ; \alpha), \lambda \in[0,1]$,

$\mathrm{D}_{\mathrm{G}} \cdot 3 \mathrm{D}_{\mathrm{G}}^{t}(\lambda x, y ; \alpha) \leq \mathrm{D}_{\mathrm{G}}^{t}(x, y ; \alpha), \lambda \geq 1$.

The generalized distance function is almost homogeneous of degree $(\alpha-1), \alpha$ and 1 in $x$ and $y, \mathrm{D}_{\mathrm{G}} .1$, and it is non-decreasing in outputs and non-increasing inputs, $\mathrm{D}_{\mathrm{G}} \cdot 2$ and $\mathrm{D}_{\mathrm{G}} .3$. It inherits its name from the fact that thanks to the $\alpha$ parameter it encompasses the partially oriented output and input distance functions introduced by Shephard (1970), as well as the hyperbolic graph distance function introduced by Färe et al. (1985:46). When $\alpha=1$, the generalized distance function equals the output distance function $\mathrm{D}_{\mathrm{O}}^{t}(x, y)=\min \left\{\phi>0:(x, y / \phi) \in \mathrm{T}^{t}\right\}, x \in \mathfrak{R}_{+}^{\mathrm{N}}, y \in \mathfrak{R}_{+}^{\mathrm{M}}$, while if $\alpha=0$ it is equivalent to the input distance function, $\mathrm{D}_{\mathrm{I}}^{t}(x, y)=\max \left\{\gamma>0:(x / \gamma, y) \in \mathrm{T}^{t}\right\}, x \in \mathfrak{R}_{+}^{\mathrm{N}}, y \in \mathfrak{R}_{+}^{\mathrm{M}}$. Finally, if $\alpha=0.5$ equation (2) becomes the square of the hyperbolic graph distance function: $\mathrm{D}_{\mathrm{H}}^{t}(x, y)=\min \left\{\theta>0:(x \theta, y / \theta) \in \mathrm{T}^{t}\right\}, x \in \mathfrak{R}_{+}^{\mathrm{N}}, y \in \mathfrak{R}_{+}^{\mathrm{M}}{ }_{1}$.

Besides variable returns to scale, the technology may exhibit global increasing, decreasing and constant returns to scale. In this latter case, the technology is defined by

$\hat{\mathrm{T}}^{t}=\left\{(\psi x, \psi y):(x, y) \in \mathrm{T}^{t}, \psi>0\right\}$,

while the generalized distance function can be denoted as:

$\hat{\mathrm{D}}_{\mathrm{G}}^{t}(x, y ; \alpha)=\min \left\{\delta>0:\left(x \delta^{1-\alpha}, y / \delta^{\alpha}\right) \in \hat{\mathrm{T}}^{t}\right\}, \quad x \in \mathfrak{R}_{+}^{\mathrm{N}}, y \in \mathfrak{R}_{+}^{\mathrm{M}}$

Under constant returns to scale (4) places a production process on the benchmark frontier represented by Isoq $\hat{\mathrm{T}}^{t}=\left\{(x, y):(x, y) \in \hat{\mathrm{T}}^{t},\left(\omega^{(1-\beta)} x, y / \omega^{\beta}\right) \notin \hat{\mathrm{T}}^{t}, 0<\omega<1,0 \leq \beta \leq\right.$ $1\}$, and can be also interpreted as a measure of productive efficiency in the sense of Farrel

\footnotetext{
${ }^{1}$ Färe and Primont (1995) show that the output and input distance functions completely characterize the technology, i.e. $\mathrm{D}_{\mathrm{O}}^{t}(x, y) \leq 1 \Leftrightarrow(x, y) \in \mathrm{T}^{t}$ and $\mathrm{D}_{\mathrm{I}}^{t}(x, y) \geq 1 \Leftrightarrow(x, y) \in \mathrm{T}^{t}$. For the generalized distance function this is also the case -Chavas and $\operatorname{Cox}(1999: 317)$ : $\mathrm{D}_{\mathrm{G}}^{t}(x, y ; \alpha) \leq 1 \Leftrightarrow(x, y) \in \mathrm{T}^{t}$.
} 
(1957) including both technical and scale efficiency criteria -as later discussed in section 4. Concerning returns to scale, an additional property is verified:

$\mathrm{D}_{\mathrm{G}} .4 \mathrm{D}_{\mathrm{G}}^{t}(x, y ; \alpha)$ is increasing (decreasing) in $\alpha$ under IRS (DRS) and independent of $\alpha$ under CRS for $(x, y) \in \mathrm{T}^{t}$.

The production possibility set shown in Figure 1 for $\mathrm{N}=\mathrm{M}=1$ reflects all feasible output-input combinations given by the state of the technology, as well as the projections of process $\left(\mathrm{x}_{i}^{t}, \mathrm{y}_{i}^{t}\right)$ on the production frontiers that correspond to the alternative distance functions definitions ${ }^{2}$. Concerning their flexibility, the most restrictive are the partially oriented output and input distance functions, which are passive with regard to their alternative orientation as either inputs or outputs are held constant. On the other hand, while the hyperbolic distance function takes into account both sides of the production process, the direction is set to weight equally inputs contraction and outputs expansion-yielding the specific path from which it inherits its name. Finally, the generalized distance function $\mathrm{D}_{\mathrm{G}}^{t}(x, y ; \alpha)$ allows the most flexible course toward the production frontier as inputs and inputs can be asymmetrically weighted depending on the choice of $\alpha$, which is exogenously determined in the model. In general $\mathrm{D}_{\mathrm{G}}^{t}(x, y ; \alpha)$ projects $\left(\mathrm{x}_{i}^{t}, \mathrm{y}_{i}^{t}\right)$ to the best practice production frontier Isoq $\mathrm{T}$, e.g. in Figure 1 if $\alpha$ were equal to 0.5 the generalized and hyperbolic distance functions would be equivalent, and their projection is denoted by $\left(\mathrm{x}_{j}^{t+}, \mathrm{y}_{j}^{t+}\right)$. But in this particular illustration where $\alpha>0.5$, the projection $\left(\mathrm{x}_{j}^{t^{*}}, \mathrm{y}_{j}^{t^{*}}\right)$ also constitutes the most productive scale size where constant returns to scale hold, and therefore it also represents the benchmark production frontier Isoq $\hat{T}^{t}$ when $\left(\mathrm{x}_{i}^{t}, \mathrm{y}_{i}^{t}\right)$ is projected by $\hat{\mathrm{D}}_{\mathrm{G}}^{t}(x, y ; \alpha)$, i.e. because of the productive optimality of $\left(\mathrm{x}_{j}^{t^{*}}, \mathrm{y}_{j}^{t^{*}}\right)$-both from a technical and a scale perspective, $\mathrm{D}_{\mathrm{G}}^{t}(x, y ; \alpha)$ and $\hat{\mathrm{D}}_{\mathrm{G}}^{t}(x, y ; \alpha)$ are equivalent distance functions -a formal discussion follows in Section 3.

\footnotetext{
${ }^{2}$ It is interesting to remark the existing relationship between the generalized distance function and its output, input and hyperbolic counterparts when the technology exhibits global constant returns to scale. In this case, the following equivalencies between the generalized and the output, input and hyperbolic distance functions can be proven: $\hat{\mathrm{D}}_{\mathrm{G}}^{t}(x, y)=\hat{\mathrm{D}}_{\mathrm{O}}^{t}(x, y)=\hat{\mathrm{D}}_{\mathrm{I}}^{t}(x, y)^{-1}=\hat{\mathrm{D}}_{\mathrm{H}}^{t}(x, y)^{2}$, where $\hat{\mathrm{D}}_{\mathrm{O}}^{t}(x, y), \hat{\mathrm{D}}_{\mathrm{I}}^{t}(x, y)$ and $\hat{\mathrm{D}}_{\mathrm{H}}^{t}(x, y)$ denote equivalent distance functions also defined on $\hat{\mathrm{T}}^{t}$. These alternative distance functions are also illustrated in Figure 1, where they are represented by the discontinuous line extensions departing from $\left(\mathrm{x}_{i}^{t}, \mathrm{y}_{i}^{t}\right)$.
} 


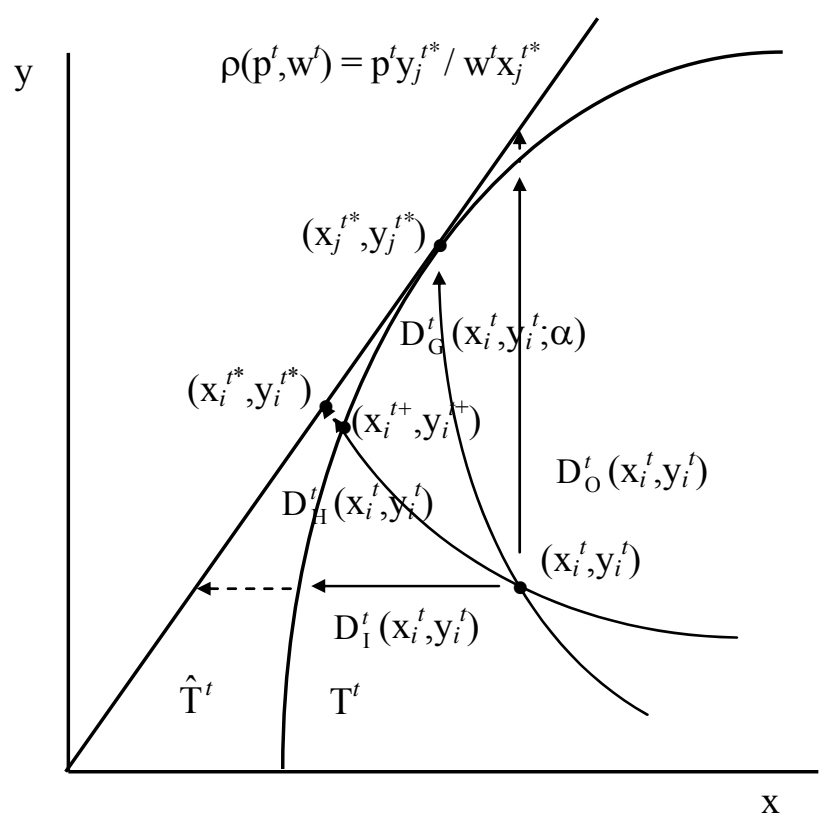

\section{Duality}

Färe and Primont (1995) summarize the duality theorems that relate the revenue function to the output distance function and the cost function to the input distance function. In this section we define the return to dollar function and show how it is dual to the generalized distance function. Let us denote the output and input price vectors in period $t$ by $p^{t} \in \mathfrak{R}_{+}^{\mathrm{M}}$ and $w^{t} \in \mathfrak{R}_{+}^{\mathrm{N}}$, and recall the time superscript for outputs and inputs quantities. The return to dollar function extensively discussed by Georgescu-Roegen (1951:103) is defined as:

$\rho\left(p^{t}, w^{t}\right)=\max _{x^{t}, y^{t}}\left\{p^{t} y^{t} / w^{t} x^{t}:\left(x^{t}, y^{t}\right) \in \mathrm{T}^{t}\right\}$

and satisfies the following properties:

P.1: $\rho\left(p^{t}, w^{t}\right)$ is nonnegative, nondecreasing in $p^{t}$ and nonincreasing in $w^{t}$,

P.2: (a) $\rho\left(\lambda p^{t}, w^{t}\right)=\lambda \rho\left(p^{t}, w^{t}\right), \lambda>0$; (b) $\rho\left(p^{t}, \lambda w^{t}\right)=\lambda^{-1} \rho\left(p^{t}, w^{t}\right), \lambda>0$; (c) $\rho\left(\lambda p^{t}, \lambda w^{t}\right)=\rho\left(p^{t}, w^{t}\right)$, P.3: $\rho\left(p^{t}, w^{t}\right)$ is convex and continuous in $p^{t}$ and $w^{t}$.

As the return to dollar function is the ratio of revenue to cost, its properties derive from those corresponding to these functions, see McFadden (1978). With regard to P.2, it is 
homogeneous of degree 1 in $p^{t},-1$ in $w^{t}$ and zero in both output and input prices. Just like its additive counterpart $\pi\left(p^{t}, w^{t}\right)=p^{t} y^{t}-w^{t} x^{t}$, (5) represents maximum profit but as a multiplicative ratio.

A relevant issue when exploring the duality between the return to dollar function and the generalized distance function comes from the fact that examining the first order conditions of the maximizing return to dollar problem (5), the production technology exhibits local constant returns to scale at the optimum. In fact, an equivalent way to express

$$
\text { is } \quad \rho\left(p^{t}, w^{t}\right) \equiv \quad \max _{x^{t}, y^{t}}\left\{p^{t} y^{t} / \mathrm{C}\left(w^{t}, y^{t}\right):\left(x^{t}, y^{t}\right) \in \mathrm{T}^{t}\right\}, \quad \text { where } \quad \mathrm{C}\left(w^{t}, y^{t}\right)=
$$
$\min _{x^{t}}\left\{w^{t} x^{t}:\left(x^{t}, y^{t}\right) \in \mathrm{L}^{t}\left(y^{t}, \mathrm{~T}^{t}\right)\right\}$. From the first order conditions: $p^{t} \mathrm{C}\left(w^{t}, y^{t}\right)=p^{t} y^{t}$ $\nabla_{y^{t}} \mathrm{C}\left(w^{t}, y^{t}\right)$, we observe that cost elasticity $\varepsilon_{\mathrm{C}}^{t}\left(w^{t}, y^{t}\right)=1$, which in turn implies that the scale elasticity is $\varepsilon^{t}\left(x^{t}, y^{t}\right)=1$ and therefore local constant returns to scale prevail ${ }^{3}$. This provides a rationale to develop the duality between the return to dollar function and the generalized distance function departing from a constant returns to scale technological specification -as in (4). For this purpose, while still allowing for a variable returns to scale technology, we show in what follows why it is satisfactory to consider such distance function as the dual counterpart to return to dollar profitability. At this economic level of analysis, this takes into account that from return to dollar perspective, the only fraction of the true but unknown technology that can be recovered is that characterized by constant return to scale ${ }^{4}$. Alternatively, from a technological perspective, the benchmark outputinput bundle maximizing return to dollar exhibits local constant returns to scale, and therefore it is scale efficient constituting a most productive scale size, e.g. in Figure 1 $\left(\mathrm{x}_{j}^{t^{*}}, \mathrm{y}_{j}^{t^{*}}\right)$ constitutes the most productive scale size complying with the constant returns to scale condition, and it also maximizes return to dollar, $\rho\left(\mathrm{p}^{t}, \mathrm{w}^{t}\right)=\mathrm{p}^{t} \mathrm{y}_{j}^{t^{*}} / \mathrm{w}^{t} \mathrm{x}_{j}^{t^{*}}$. Alternatively, a production process that is scale inefficient does not fulfill the local constant returns to scale condition, and cannot maximize return to dollar, e.g. $\left(\mathrm{x}_{i}^{t^{+}}, \mathrm{y}_{i}^{t^{+}}\right)$.

\footnotetext{
${ }^{3}$ This result connects with Georgescu-Roegen's (1951) claim identifying the return to dollar function as “.... an economic criterion on which to base the choice between two linear processes...must be independent of the scale of production, whereas $p^{t} y^{t}, w^{t} x^{t}$, and $p^{t} y^{t}-w^{t} x^{t}$ are not" -his italics and our notation. The choice for a profitability performance measure independent of returns to scale is also desirable when relating the generalized distance function to productivity indexes, which in principle should satisfy a proportionality property -and this, in turn, requires a constant returns to scale technology specification, Balk (2001).

${ }^{4}$ Therefore, the unknown technology can exhibit variable returns to scale, but those loci where the technology exhibits those returns are irrelevant or superfluous to the determination of the return to dollar maximizing behavior of the production process. This constitutes McFadden's (1978:22) envelopment technology which is
} 
We now demonstrate how the generalized distance function defined on the constant returns to scale technology allows us characterize the relevant constant return to scale technology that can be recovered from the return to dollar function, and to assess the distance between any production process and the most productive scale benchmarks that comply with the optimal scale condition and may maximize return to dollar. Here we extend the discussion found in Balk (2001) to the generalized distance function case. Let us consider the $i$-th production process $\left(x_{i}^{t}, y_{i}^{t}\right) \in \mathrm{T}^{t}$ and express the production technology in terms of the output production possibility set $\left.\mathrm{P}^{t}\left(x_{i}^{t}, \mathrm{~T}^{t}\right)=\left\{y_{i}:\left(x_{i}^{t}, y_{i}^{t}\right) \in \mathrm{T}^{t}\right)\right\}$, whose isoquant subset defines as Isoq $\mathrm{P}^{t}\left(\omega^{1-\beta} x, \mathrm{~T}^{t}\right)=\left\{y: y \in \mathrm{P}^{t}\left(\omega^{1-\beta} x\right), y / \omega^{\beta} \notin \mathrm{P}^{t}\left(\omega^{1-\beta} x\right), 0<\omega<1,0 \leq \beta \leq 1\right\}$. For analytical purposes let us multiply inputs by $\lambda>0$. In this case the vector $y / D_{\mathrm{G}}^{t}\left(\lambda x_{i}^{t}, y_{i}^{t} ; \alpha\right)^{\alpha}$ is technically efficient by belonging to Isoq $\mathrm{P}^{t}\left(\lambda \mathrm{D}_{\mathrm{G}}^{t}\left(\lambda x_{i}^{t}, y_{i}^{t} ; \alpha\right)^{1-\alpha} x_{i}, \mathrm{~T}^{t}\right)$. Simplifying notation by $\mu=1 / \mathrm{D}_{\mathrm{G}}^{t}\left(\lambda x_{i}^{t}, y_{i}^{t} ; \alpha\right)^{\alpha}$ and $\nu=\lambda \mathrm{D}_{\mathrm{G}}^{t}\left(\lambda x_{i}^{t}, y_{i}^{t} ; \alpha\right)^{1-\alpha}$, it is possible that for some of these technically efficient processes, their $\mu / v$ ratio is not the highest one, signaling that their particular operating scales do not yield the highest productivity, i.e. as we shall recall later on, they are scale inefficient. Therefore, we want to search for the value of $\lambda^{*}$ that maximizes the ratio

$$
\max _{\lambda} \frac{\mu}{\nu}=\max _{\lambda} \frac{1 / \mathrm{D}_{\mathrm{G}}^{t}\left(\lambda x_{i}^{t}, y_{i}^{t} ; \alpha\right)^{\alpha}}{\lambda \cdot \mathrm{D}_{\mathrm{G}}^{t}\left(\lambda x_{i}^{t}, y_{i}^{t} ; \alpha\right)^{1-\alpha}}=\frac{1}{\min _{\lambda} \lambda \cdot \mathrm{D}_{\mathrm{G}}^{t}\left(\lambda x_{i}^{t}, y_{i}^{t} ; \alpha\right)}=\frac{1}{\min _{\lambda} \mathrm{D}_{\mathrm{G}}^{t}\left(\lambda^{\alpha} x_{i}^{t}, \lambda^{\alpha} y_{i}^{t} ; \alpha\right)},
$$

where the last equality follows from the almost homogeneity property $\mathrm{D}_{\mathrm{G}} .1$. When $\lambda^{*}$ exists, the process $\left(\lambda^{*} x_{i}^{t} \mathrm{D}_{\mathrm{G}}^{t}\left(\lambda^{*} x_{i}^{t}, y_{i}^{t} ; \alpha\right)^{1-\alpha}, y_{i}^{t} / \mathrm{D}_{\mathrm{G}}^{t}\left(\lambda^{*} x_{i}^{t}, y_{i}^{t} ; \alpha\right)^{\alpha}\right)$ represents a most productive scale size, i.e. a benchmark optimal scale. Looking at the first-order condition of the optimizing problem, we can confirm that scale elasticity is one ${ }^{5}$

$$
\left.\varepsilon^{t}\left(\lambda^{*} x_{i}^{t} \mathrm{D}_{\mathrm{G}}^{t}\left(\lambda^{*} x_{i}^{t}, y_{i}^{t} ; \alpha\right)^{1-\alpha}, y_{i}^{t} / \mathrm{D}_{\mathrm{G}}^{t}\left(\lambda^{*} x_{i}^{t}, y_{i}^{t} ; \alpha\right)^{\alpha}\right)\right)=1,
$$

characterized by the generalized distance function defined on constant returns to scale specification. The envelopment technology is represented in Figure 1 by $\hat{T} \subseteq \mathrm{T}$-and, therefore, Isoq $\hat{\mathrm{T}} \subseteq \mathrm{Isoq} \mathrm{T}$.

${ }^{5}$ The local scale elasticity reflects the sensitivity of the generalized distance function with respect to a proportional change in outputs and inputs. For the multiple ouput-input case, if the generalized distance function is continuously differentiable, the local scale elasticity function at $\left(x^{t}, y^{t}\right)$ is given by $\varepsilon^{t}\left(x^{t}, y^{t}\right) \equiv$ $-\left(\nabla_{x^{t}} \mathrm{D}_{\mathrm{G}}^{t}\left(x^{t}, y^{t} ; \alpha\right) \cdot x^{t}\right) /\left(\nabla_{y^{t}} \mathrm{D}_{\mathrm{G}}^{t}\left(x^{t}, y^{t} ; \alpha\right) \cdot y^{t}\right)$. 
and the technology exhibits local constant returns to scale at the optimal scale process. If we recall the global constant returns to scale technology (3) along with the generalized distance function definition (2), and denote $\lambda^{\alpha}=\psi$, then

$$
\begin{aligned}
\min _{\lambda} \mathrm{D}_{\mathrm{G}}^{t}\left(\lambda^{\alpha} x_{i}^{t}, \lambda^{\alpha} y_{i}^{t} ; \alpha\right) & =\min _{\lambda} \min \left\{\delta>0:\left(\psi x_{i}^{t} \delta^{1-\alpha}, \psi y_{i}^{t} / \delta^{\alpha}\right) \in \mathrm{T}^{t}\right\} \\
= & \min \left\{\delta>0:\left(x_{i}^{t} \delta^{1-\alpha}, y_{i}^{t} / \delta^{\alpha}\right) \in \hat{\mathrm{T}}^{t}\right\} \text { (given definition (3)) } \\
= & \hat{\mathrm{D}}_{\mathrm{G}}^{t}\left(x_{i}^{t}, y_{i}^{t} ; \alpha\right),
\end{aligned}
$$

and the generalized distance function (2) can be interpreted as the distance separating a process's productivity from that achieved at optimal scale. Equation (8) shows that when the generalized distance function defined on a variable returns to scale technology can be interpreted in such way -as required by the analytical developments in section 4 where return to dollar efficiency is introduced, it is equivalent to its definition on a global constant returns to scale technology (4), which is what it is needed when defining the duality between the generalized distance function and the return to dollar function, whose maximization requires constant returns to scale. Coming back to Figure 1, let us consider once again $\alpha=0.5$ rendering $\mathrm{D}_{\mathrm{G}}^{t}\left(\mathrm{x}_{i}^{t}, \mathrm{y}_{i}^{t} ; \alpha\right)=\mathrm{D}_{\mathrm{H}}^{t}\left(\mathrm{x}_{i}^{t}, \mathrm{y}_{i}^{t}\right)^{2}$. In this case, the projection of $\left(\mathrm{x}_{i}^{t}, \mathrm{y}_{i}^{t}\right)$ on the best practice production frontier represented by Isoq $\mathrm{T}^{t}-\left(\mathrm{x}_{i}^{t^{+}}, \mathrm{y}_{i}^{t+}\right)$, does not constitute the most productive scale size and does not satisfy the constant returns to scale condition for return to dollar maximization. But following equation (8) we formally show that its projection $\left(\mathrm{x}_{i}^{t^{*}}, \mathrm{y}_{i}^{t^{*}}\right)$ by way of $\hat{\mathrm{D}}_{\mathrm{G}}^{t}\left(\mathrm{x}_{i}^{t}, \mathrm{y}_{i}^{t} ; 0.5\right)=\hat{\mathrm{D}}_{\mathrm{H}}^{t}\left(\mathrm{x}_{i}^{t}, \mathrm{y}_{i}^{t}\right)^{2}$ belongs to the envelopment benchmark production frontier Isoq $\hat{\mathrm{T}}^{t}$, which is determined by the relevant locus constituting the most productive scale size $\left(\mathrm{x}_{j}^{t^{*}}, \mathrm{y}_{j}^{t^{*}}\right)$, and therefore measures the distance to the highest productivity level.

When $\hat{\mathrm{D}}_{\mathrm{G}}^{t}\left(x_{i}^{t}, y_{i}^{t} ; \alpha\right)=1$ the technically efficient process is also scale efficient by producing at optimal scale, belongs to the benchmark frontier represented by Isoq $\hat{\mathrm{T}}^{t}$, and constitutes a candidate for return to dollar maximization. In a multiple output-multiple input setting several most productive scale sizes may exit. However, not all most productive processes maximize return to dollar because the different output and inputs prices constitute particular aggregating functions that signal which producer maximizes profitability at the prevailing market prices. In this context, even if from a technological perspective several processes may produce at the benchmark optimal scale frontiers where local scale elasticity is 
one and constant returns to scale hold, just those that suit price aggregation will maximize the return to dollar function, i.e. they are dual to each other.

We can then turn to state the duality between the return to dollar function and the generalized distance function defined on the constant returns to scale specification of the technology (3). We must firstly show that corresponding to every input-output production possibility set there is a return to dollar function with properties P.1-P.3. This is equivalent to state that the return to dollar function determines an implicit production possibility set that, given the optimal scale condition, characterizes by constant returns to scale, i.e. it is possible to derive or recover $\hat{\mathrm{T}}^{t}$ from the return to dollar function. This can be summarized in the following:

Proposition 1: If the return to dollar function is defined by $\rho\left(p^{t}, w^{t}\right)=$ $\max _{x^{t}, y^{t}}\left\{p^{t} y^{t} / w^{t} x^{t}:\left(x^{t}, y^{t}\right) \in \hat{\mathrm{T}}^{t}\right\}$, then $\hat{T}^{t}=\left\{\left(x^{t}, y^{t}\right): p^{t} y^{t} / w^{t} x^{t} \leq \rho\left(p^{t}, w^{t}\right)\right\}$, for all $p^{t}>0$ and $w^{t}>0$,

which can be conversely expressed by way of

Proposition 2: If $\hat{\mathrm{T}}^{t}=\left\{\left(x^{t}, y^{t}\right): p^{t} y^{t} / w^{t} X^{t} \leq \rho\left(p^{t}, w^{t}\right)\right.$, for all $p^{t}>0$ and $\left.w^{t}>0\right\}$, then $\rho\left(p^{t}, w^{t}\right)=\max _{x^{t}, y^{t}}\left\{p^{t} y^{t} / w^{t} x^{t}:\left(x^{t}, y^{t}\right) \in \hat{\mathrm{T}}^{t}\right\}$.

Propositions (1) and (2), which can be proven along the lines of McFadden (1978:23) and Färe and Primont (1995: 73-74) ${ }^{6}$, establish the duality between the return to dollar function and the relevant technology set. Considering the distance function representation of the technology set given in section two, we can extend the analysis to the following duality between the return to dollar function and the generalized distance function. Since the generalized distance function completely characterizes the technology,

$\rho\left(p^{t}, w^{t}\right)=\max _{x^{t}, y^{t}}\left\{p^{t} y^{t} / w^{t} x^{t}: \hat{\mathrm{D}}_{\mathrm{G}}^{t}\left(x^{t}, y^{t} ; \alpha\right) \leq 1\right\}, p^{t}>0, w^{t}>0$

\footnotetext{
${ }^{6}$ Considering once again the following expression of the return to dollar function: $\rho\left(p^{t}, w^{t}\right) \equiv$ $\max _{x^{t}, y^{t}}\left\{p^{t} y^{t} / \mathrm{C}\left(w^{t} y^{t}\right):\left(x^{t}, y^{t}\right) \in \hat{\mathrm{T}}^{t}\right\}$, where $\mathrm{C}\left(w^{t}, y^{t}\right)=\min _{x^{t}}\left\{w^{t} x^{t}:\left(x^{t}, y^{t}\right) \in \mathrm{L}^{t}\left(y, \hat{\mathrm{T}}^{t}\right)\right\}$, maximizing return to dollar is equivalent to minimize cost for the existing output levels, $y^{t}$, and output prices $p^{t}$, i.e. revenue value,
} 
if and only if

$$
\hat{\mathrm{D}}_{\mathrm{G}}^{t}\left(x^{t}, y^{t} ; \alpha\right)=\max _{p^{t}, w^{t}}\left\{p^{t} y^{t} / w^{t} x^{t}: \rho\left(p^{t}, w^{t}\right) \leq 1\right\}, x^{t} \in \mathfrak{R}_{+}^{\mathrm{N}}, y^{t} \in \mathfrak{R}_{+}^{\mathrm{M}} .
$$

Therefore, if the return to dollar function is derived from the generalized distance function by maximizing revenue to cost over all feasible input-output quantity vectors, then the generalized distance function can be recovered from the return to dollar function by finding the maximum of revenue to cost over all feasible input-output price vectors. Equivalently, if we derive the generalized distance function from the return to dollar function and then derive this last function from the generalized distance function, the resulting derived return to dollar function is the same as the original return to dollar function.

Finally, it is possible to provide the following definitions of the return to dollar and generalized distance function equivalent to (9) and (10):

$$
\rho\left(p^{t}, w^{t}\right)=\max _{x^{t}, y^{t}}\left\{\frac{p^{t} y^{t} / \hat{\mathrm{D}}_{\mathrm{G}}^{t}\left(x^{t}, y^{t} ; \alpha\right)^{\alpha}}{w^{t} x^{t} \cdot \hat{\mathrm{D}}_{\mathrm{G}}^{t}\left(x^{t}, y^{t} ; \alpha\right)^{1-\alpha}}\right\}, p^{t}>0, w^{t}>0
$$

and

$$
\hat{\mathrm{D}}_{\mathrm{G}}^{t}\left(x^{t}, y^{t} ; \alpha\right)=\max _{p^{t}, w^{t}}\left\{\frac{p^{t} y^{t} / w^{t} x^{t}}{\rho\left(p^{t}, w^{t}\right)}\right\}, x^{t} \in \mathfrak{R}_{+}^{\mathrm{N}}, y^{t} \in \mathfrak{R}_{+}^{\mathrm{M}},
$$

implying that

$$
\rho\left(p^{t}, w^{t}\right) \geq\left(p^{t} y^{t} / \hat{\mathrm{D}}_{\mathrm{G}}^{t}\left(x^{t}, y^{t} ; \alpha\right)^{\alpha}\right) /\left(w^{t} x^{t} \cdot \hat{\mathrm{D}}_{\mathrm{G}}^{t}\left(x^{t}, y^{t} ; \alpha\right)^{1-\alpha}\right) \geq\left(p^{t} y^{t} / w^{t} x^{t}\right) / \hat{\mathrm{D}}_{\mathrm{G}}^{t}\left(x^{t}, y^{t} ; \alpha\right) .
$$

This last expression, which corresponds to the Mahler inequality in the present generalized context, can be modified along the lines introduced by Färe and Grosskopf (2000) to represent technical and allocative inefficiency.

$p^{t} y^{t}$. Therefore, the exiting duality theorems between the cost function and the input production possibility set can be extended to the return to dollar function and the technology set. 


\section{Efficiency and Productivity Measurement}

The choice of the return to dollar function as an economic criterion to select between alternative production processes was already proposed by Georgescu-Roegen (1951:103). Therefore, the return to dollar function can be considered as the benchmark against which to confront economic performance. In this section we show how to assess such performance in terms of technical and allocative efficiency analysis. To achieve this goal, we provide a technical efficiency interpretation of the generalized distance function, and enhance it with a residual allocative efficiency term that captures the disparity between the return to dollar maximizing input and output combination and the efficient projection of any observed production process on the benchmark production frontier ${ }^{7}$.

Building on Georgescu-Roegen's idea of comparing processes by way of the return to dollar function, it is possible to define the following profit efficiency measure:

$\operatorname{RDE}^{t}\left(x^{t}, y^{t}, p^{t}, w^{t}\right)=\left(p^{t} y^{t} / w^{t} x^{t}\right) / \rho\left(p^{t}, w^{t}\right)$,

which compares actual return to dollar profitability with the maximum return to dollar value consistent with the production technology. To accomplish a meaningful decomposition of (14) assessing the sources of potential return to dollar inefficiency we need to introduce the concepts of technical and scale efficiency.

On one hand the generalized distance function (2) can be regarded a technical efficiency measure as it values how far a process situates from the best practice variable returns to scale production frontier Isoq $\mathrm{T}^{t}$,

$\mathrm{TE}^{t}\left(x^{t}, y^{t} ; \alpha\right)=\mathrm{D}_{\mathrm{G}}^{t}\left(x^{t}, y^{t} ; \alpha\right)$

On the other hand, we have shown in the previous section -equations (6), (7) and (8) - that the generalized distance function defined on a global constant returns to scale technology measures the relative difference between actual productivity at current scale size and the highest one corresponding to the benchmark optimal scale frontier Isoq $\hat{\mathrm{T}}^{t}$. In

\footnotetext{
${ }^{7}$ Chambers et al. (1998) establish parallel notions to those proposed in this article for efficiency measurement making use of directional distance functions, which are dual for the standard additive profit function.
} 
fact, the duality between the generalized and the return to dollar functions is based on the grounds that this function represents the distance separating any production process from the most productive scale sizes, and therefore comply with the necessary local constant returns to scale condition that makes them candidates to maximize return to dollar. This allows us to interpret the constant returns to scale distance function specification (4) as a measure of productive efficiency:

$\operatorname{PE}^{t}\left(x^{t}, y^{t} ; \alpha\right)=\hat{\mathrm{D}}_{\mathrm{G}}^{t}\left(x^{t}, y^{t} ; \alpha\right)$.

Relaying on these definitions, any difference between the variable and constant returns to scale generalized distance functions would show that the production process, when projected toward the best practice production frontier, does not situate on the relevant optimal constant returns to scale loci that would make it scale efficient -and suitable for return to dollar maximization. On these grounds it is possible to define a scale efficiency measure as the ratio of (4) to (2):

$\mathrm{SE}^{t}\left(x^{t}, y^{t} ; \alpha\right)=\hat{\mathrm{D}}_{\mathrm{G}}^{t}\left(x^{t}, y^{t} ; \alpha\right) / \mathrm{D}_{\mathrm{G}}^{t}\left(x^{t}, y^{t} ; \alpha\right)$

Substituting (15) and (17) into (16), productive efficiency can decomposed in a technical component capturing the distance between a process and its variable returns to scale best practice frontier and a scale component representing how far the technically efficient projected process is from the benchmark frontier represented by the most productive scale sizes, i.e. $\mathrm{PE}^{t}=\hat{\mathrm{D}}_{\mathrm{G}}^{t}\left(x^{t}, y^{t} ; \alpha\right)=\mathrm{D}_{\mathrm{G}}^{t}\left(x^{t}, y^{t} ; \alpha\right) \cdot \mathrm{SE}^{t}=\mathrm{TE}^{t} \cdot \mathrm{SE}^{t}$.

It is now possible to take the last step to achieve the decomposition of the distance between observed and maximum return to dollar. Coming back to (13) it is possible to rearrange this expression in the following way: $\left(p^{t} y^{t} / w^{t} x^{t}\right) / \rho\left(p^{t}, w^{t}\right) \leq \hat{\mathrm{D}}_{\mathrm{G}}^{t}\left(x^{t}, y^{t} ; \alpha\right)$, which can be rendered an equality introducing an allocative efficiency term ( $\left.\mathrm{AE}^{t}\right)$ representing the distance between observed return to dollar at the scale efficient projections and maximum return to dollar at the optimal scale size. Proceeding this way, and substituting technical and scale efficiency for productive efficiency, we obtain the following equality: $\left(p^{t} y^{t} / w^{t} x^{t}\right) / \rho\left(p^{t}, w^{t}\right)=\mathrm{D}_{\mathrm{G}}^{t}\left(x^{t}, y^{t} ; \alpha\right) \cdot \mathrm{SE}^{t} \cdot \mathrm{AE}^{t}$. Therefore, allocative efficiency is given by 
$\operatorname{AE}^{t}\left(x^{t}, y^{t}, p^{t}, w^{t} ; \alpha\right)=\frac{\left(p^{t} y^{t} / w^{t} x^{t}\right) / \hat{\mathrm{D}}_{\mathrm{G}}^{t}\left(x^{t}, y^{t} ; \alpha\right)}{\rho\left(p^{t}, w^{t}\right)}$

Expressions (14) through (18) allow the decomposition of the overall return to dollar efficiency consistent with Farrell's (1957) proposal, i.e. $\mathrm{RDE}^{t}=\mathrm{PE}^{t} \cdot \mathrm{AE}^{t}=\mathrm{TE}^{t} \cdot \mathrm{SE}^{t}$ - $\mathrm{AE}^{t}$. With regard to some key values of $\mathrm{RDE}^{t}$, it is nonnegative for any feasible production process $\left(x^{t}, y^{t}\right)$ and, in the event of a process that is return to dollar efficient, then it is technical, scale and allocative efficient, equaling one. Also note that through duality, when allocative efficiency is assumed, return to dollar efficiency is equivalent to the constant returns to scale generalized distance function (4). In Figure $1\left(\mathrm{x}_{i}^{t}, \mathrm{y}_{i}^{t}\right)$ would be technical and scale inefficient with $\mathrm{RDE}^{t}<1$ if directed to the frontier by way of $\hat{\mathrm{D}}_{\mathrm{G}}^{t}\left(\mathrm{x}_{i}^{t}, \mathrm{y}_{i}^{t} ; 0.5\right)=\hat{\mathrm{D}}_{\mathrm{H}}^{t}\left(\mathrm{x}_{i}^{t}, \mathrm{y}_{i}^{t}\right)^{2}$, while its projection to the benchmark production frontier by way of the generalized distance function is just technically inefficient.

We can now recall the productivity interpretation of the overall return to dollar efficiency $\mathrm{RDE}^{t}$. Given the input and output prices in period $t$, it is possible to assess the relative profitability of the $i$-th process $\left(x_{i}^{t}, y_{i}^{t}\right)$ relative to the $j$-th process, which we assume maximizes return to dollar and therefore is economically efficient in time $t$, i.e. $\left(x_{j}^{t}, y_{j}^{t}\right)=$ $\left(x_{j}^{t^{*}}, y_{j}^{t^{*}}\right)$ and $\mathrm{RDE}_{j}^{t}=1$-as illustrated in Figure 1. In this case it is possible to define the following productivity index that allows for a binary comparison between the outputs to inputs ratio of process $i$ relative to the optimal process $j$ :

$$
\begin{aligned}
Q^{t, t}\left(p^{t}, w^{t}, x_{i}^{t}, y_{i}^{t}, x_{j}^{t^{*}}, y_{j}^{t^{*}}\right) & =\frac{p^{t} y_{i}^{t} / w^{t} x_{i}^{t}}{p^{t} y_{j}^{t^{*}} / w^{t} x_{j}^{t^{*}}}=\frac{p^{t} y_{i}^{t} / w^{t} x_{i}^{t}}{\rho\left(p^{t}, w^{t}\right)}=\hat{\mathrm{D}}_{\mathrm{G}}^{t}\left(x^{t}, y^{t} ; \alpha\right) \cdot \mathrm{AE}^{t}= \\
& =\mathrm{D}_{\mathrm{G}}^{t}\left(x^{t}, y^{t} ; \alpha\right) \cdot \mathrm{SE}^{t} \cdot \mathrm{AE}^{t}=\mathrm{TE}^{t} \cdot \mathrm{SE}^{t} \cdot \mathrm{AE}^{t}=\mathrm{RDE}^{t}
\end{aligned}
$$

where the first and second superscripts in $Q^{t, t}$ correspond to the periods in which the aggregating prices and the evaluated processes are considered. Therefore, we conclude that the overall return to dollar efficiency measure can be interpreted as a productivity index comparing current profitability relative to the return to dollar function. 


\section{Efficiency and Productivity Change Measurement}

Extending the above definitions to a dynamic context allows us to show that the usual Laspeyres, Paasche and Fisher productivity indexes can be directly related to specific Malmquist productivity indexes, which in turn enables their decomposition according to technical and economic criteria. Let us consider price and quantity vectors of inputs and outputs relative to a base period $t=0$ and a comparison period $t=1$. Defining (19) for both periods, and dividing the comparison period index by the base period index, one obtains the following return to dollar overall efficiency change index:

$$
\begin{aligned}
Q_{R D} & =\frac{Q^{1,1}\left(p^{1}, w^{1}, x_{i}^{1}, y_{i}^{1}, x_{j}^{1^{*}}, y_{j}^{1^{*}}\right)}{Q^{0,0}\left(p^{0}, w^{0}, x_{i}^{0}, y_{i}^{0}, x_{j}^{0^{*}}, y_{j}^{0^{*}}\right)}=\frac{\frac{p^{1} y_{i}^{1} / w^{1} x_{i}^{1}}{p^{1} y_{j}^{1 *^{*}} / w^{1} x_{j}^{1^{*}}}}{\frac{p^{0} y_{i}^{0} / w^{0} x_{i}^{0}}{p^{0} y_{j}^{0^{*}} / w^{0} x_{j}^{0^{*}}}}=\frac{\frac{p^{1} y_{i}^{1} / w^{1} x_{i}^{1}}{\rho\left(p^{1}, w^{1}\right)}}{\frac{p^{0} y_{i}^{0} / w^{0} x_{i}^{0}}{\rho\left(p^{0}, w^{0}\right)}}= \\
& =\frac{\hat{\mathrm{D}}_{\mathrm{G}}^{1}\left(x_{i}^{1}, y_{i}^{1} ; \alpha\right)}{\hat{\mathrm{D}}_{\mathrm{G}}^{0}\left(x_{i}^{0}, y_{i}^{0} ; \alpha\right)} \cdot \frac{\mathrm{AE}^{1}\left(p^{1}, w^{1}, x_{i}^{1}, y_{i}^{1} ; \alpha\right)}{\mathrm{AE}^{0}\left(p^{0}, w^{0}, x_{i}^{0}, y_{i}^{0} ; \alpha\right)}=\mathrm{PEC}^{0,1} \cdot \mathrm{AEC}^{0,1}= \\
& =\frac{\mathrm{D}_{\mathrm{G}}^{1}\left(x_{i}^{1}, y_{i}^{1} ; \alpha\right)}{\mathrm{D}_{\mathrm{G}}^{0}\left(x_{i}^{0}, y_{i}^{0} ; \alpha\right)} \cdot \frac{\mathrm{SE}^{1}\left(x_{i}^{1}, y_{i}^{1} ; \alpha\right)}{\mathrm{SE}^{0}\left(x_{i}^{0}, y_{i}^{0} ; \alpha\right)} \cdot \frac{\mathrm{AE}^{1}\left(p^{1}, w^{1}, x_{i}^{1}, y_{i}^{1} ; \alpha\right)}{\mathrm{AE}^{0}\left(p^{0}, w^{0}, x_{i}^{0}, y_{i}^{0} ; \alpha\right)}= \\
& =\mathrm{TEC}^{0,1} \cdot \mathrm{SEC}^{0,1} \cdot \mathrm{AEC}^{0,1}=\mathrm{RDEC}^{0,1},
\end{aligned}
$$

which compares the revenue to cost ratio of process $i$ relative to the maximizing revenue to cost ratio in two consecutive periods. If it is greater than one then process $i$ increases its overall return to dollar efficiency. Values less than one indicate worsening efficiency, while if it is equal to one then its relative situation with respect to the return to dollar maximizing processes has not changed. The interpretation of these values with regard to the technical, scale and allocative efficiency is analogous. $\mathrm{TEC}^{0,1}$ represents the change in relative technical efficiency or how far is the processs from each period best practice production frontier. Following Färe et al. (1994), SEC ${ }^{0,1}$ shows if the distance between the technically efficient projections and the benchmark optimal scale frontier has increased or reduced. Finally, $\mathrm{AEC}^{0,1}$ measures the change in allocative efficiency, i.e. once the process is projected to the benchmark optimal scale frontier in both periods, it measures how far these projections are from the maximizing return to dollar vectors.

Once efficiency change has been established, we can deal with productivity change by relating the Laspeyres, Paasche and Fisher productivity indexes to their Malmquist 
counterparts. To attain this goal we firstly need to allow for intertemporal comparisons of the return to dollar overall measure. Let us consider the $i$-th production process observed in the comparison period: $\left(x_{i}{ }^{1}, y_{i}{ }^{1}\right)$, and define its relative overall efficiency with regard to maximum return to dollar in the base period. In this case, (19) becomes

$$
\begin{aligned}
& Q^{0,1}\left(p^{0}, w^{0}, x_{i}^{1}, y_{i}^{1}, x_{j}^{0^{*}}, y_{j}^{0^{*}}\right)=\frac{p^{0} y_{i}^{1} / w^{0} x_{i}^{1}}{p^{0} y_{j}^{0^{*}} / w^{0} x_{j}^{0^{*}}}=\frac{p^{0} y_{i}^{1} / w^{0} x_{i}^{1}}{\rho\left(p^{0}, w^{0}\right)}=\hat{\mathrm{D}}_{\mathrm{G}}^{0}\left(x_{i}^{1}, y_{i}^{1} ; \alpha\right) \cdot \mathrm{A}^{0}\left(p^{0}, w^{0}, x_{i}^{1}, y_{i}^{1} ; \alpha\right)= \\
& \quad=\mathrm{D}_{\mathrm{G}}^{0}\left(x_{i}^{1}, y_{i}^{1} ; \alpha\right) \cdot \mathrm{S}^{0}\left(x_{i}^{1}, y_{i}^{1} ; \alpha\right) \cdot \mathrm{A}^{0}\left(p^{0}, w^{0}, x_{i}^{1}, y_{i}^{1} ; \alpha\right) \\
& =\mathrm{T}^{0}\left(x_{i}^{1}, y_{i}^{1} ; \alpha\right) \cdot \mathrm{S}^{0}\left(x_{i}^{1}, y_{i}^{1} ; \alpha\right) \cdot \mathrm{A}^{0}\left(p^{0}, w^{0}, x_{i}^{1}, y_{i}^{1} ; \alpha\right)=\mathrm{RD}^{0}\left(x_{i}^{1}, y_{i}^{1}\right),
\end{aligned}
$$

where the mix period generalized distance function for process $i$ defines in an analogous way to (2) and (4), i.e. $\mathrm{D}_{\mathrm{G}}^{0}\left(x_{i}^{1}, y_{i}^{1} ; \alpha\right)=\min \left\{\delta>0:\left(x_{i}^{1} \delta^{1-\alpha}, y_{i}^{1} / \delta^{\alpha}\right) \in \mathrm{T}^{0}\right\}, x \in \mathfrak{R}_{+}^{\mathrm{N}}, y \in \mathfrak{R}_{+}^{\mathrm{M}}$ and $\hat{\mathrm{D}}_{\mathrm{G}}^{0}\left(x_{i}^{1}, y_{i}^{1} ; \alpha\right)=\min \left\{\delta>0:\left(x_{i}^{1} \delta^{1-\alpha}, y_{i}^{1} / \delta^{\alpha}\right) \in \hat{\mathrm{T}}^{0}\right\}, x \in \mathfrak{R}_{+}^{\mathrm{N}}, y \in \mathfrak{R}_{+}^{\mathrm{M}}$. The technical term $\mathrm{T}^{0}\left(x_{i}{ }^{1}, y_{i}{ }^{1}\right)$ captures how far is the comparison period process from the base period best practice production frontier. Analogously, the scale term $\mathrm{S}^{0}\left(x_{i}{ }^{1}, y_{i}{ }^{1} ; \alpha\right)$ determines how far is its technical projection to best practice in the base period, from the base period benchmark optimal scale frontier. Finally, $\mathrm{A}^{0}\left(p^{0}, w^{0}, x_{i}{ }^{1}, y_{i}{ }^{1} ; \alpha\right)=\left[\left(p^{0} y^{0} / w^{1} x^{1}\right) / \hat{\mathrm{D}}_{\mathrm{G}}^{0}\left(x^{1}, y^{1} ; \alpha\right)\right] / \rho\left(p^{0}, w^{0}\right)$ denotes the residual allocative term corresponding to the comparison of the return to dollar attained by process $i$ once projected on the base period benchmark optimal scale, with maximum return to dollar in that same period. Although this term has the formal structure of (18), it cannot be consider as measuring allocative efficiency since the comparison period process $\left(x_{i}{ }^{1}, y_{i}{ }^{1}\right)$ is not consistently evaluated against its own period maximum return to dollar $\rho\left(p^{1}, w^{1}\right)$, but against the base period benchmark $\rho\left(p^{0}, w^{0}\right)$. It is likely that, in a productivity growth context, the return to dollar value of process $i$ in the comparison period given by (21) exceeds the maximum value observed in the base period. In this case the relative return to dollar overall efficiency may be greater than one, and since the input and output price vectors are those observed in the base period, this result corresponds to the presence of higher productivity if $\hat{\mathrm{D}}_{\mathrm{G}}^{0}\left(x_{i}^{1}, y_{i}^{1} ; \alpha\right)>1$ and technological progress if $\mathrm{D}_{\mathrm{G}}^{0}\left(x_{i}^{1}, y_{i}^{1} ; \alpha\right)>1$-showing respectively that $\left(x_{i}{ }^{1}, y_{i}{ }^{1}\right) \notin \hat{\mathrm{T}}^{0}$ and $\left(x_{i}{ }^{1}, y_{i}{ }^{1}\right) \notin \mathrm{T}^{0}$. Therefore when $\hat{\mathrm{D}}_{\mathrm{G}}^{0}\left(x_{i}^{1}, y_{i}^{1} ; \alpha\right)>1$, then $\mathrm{RD}^{0}\left(x_{i}{ }^{1}, y_{i}^{1}\right)>1$ with $\mathrm{A}^{0}\left(p^{0}, w^{0}, x_{i}^{1}, y_{i}^{1}\right) \leq 1$. 
We can now proceed to assess how economic performance evolves in time with respect to a base period. For the production process $i$ in the base and comparison periods: $\left(x_{i}^{0}, y_{i}^{0}\right)$ and $\left(x_{i}^{1}, y_{i}^{1}\right)$, this can be achieved by comparing its intertemporal return to dollar efficiency measure (21) to its contemporaneous base period efficiency -as defined in (19). Proceeding this way we obtain the following relationship between the Laspeyres productivity index and the base period Malmquist productivity index:

$$
\begin{aligned}
Q_{L} & =\frac{Q^{0,1}\left(p^{0}, w^{0}, x_{i}^{1}, y_{i}^{1}, x_{j}^{0^{*}}, y_{j}^{0^{*}}\right)}{Q^{0,0}\left(p^{0}, w^{0}, x_{i}^{0}, y_{i}^{0}, x_{j}^{0^{*}}, y_{j}^{0^{*}}\right)}=\frac{\frac{p^{0} y_{i}^{1} / w^{0} x_{i}^{1}}{p^{0} y_{j}^{0^{*}} / w^{0} x_{j}^{0^{*}}}}{\frac{p^{0} y_{i}^{0} / w^{0} x_{i}^{0}}{p^{0} y_{j}^{0^{*}} / w^{0} x_{j}^{0^{*}}}}=\frac{\frac{p^{0} y_{i}^{1} / w^{0} x_{i}^{1}}{\rho\left(p^{0}, w^{0}\right)}}{\frac{p^{0} y_{i}^{0} / w^{0} x_{i}^{0}}{\rho\left(p^{0}, w^{0}\right)}}=\frac{p^{0} y_{i}^{1} / w^{0} x_{i}^{1}}{p^{0} y_{i}^{0} / w^{0} x_{i}^{0}}= \\
& =\frac{\hat{\mathrm{D}}_{\mathrm{G}}^{0}\left(x_{i}^{1}, y_{i}^{1} ; \alpha\right)}{\hat{\mathrm{D}}_{\mathrm{G}}^{0}\left(x_{i}^{0}, y_{i}^{0} ; \alpha\right)} \cdot \frac{\mathrm{A}^{0}\left(p^{0}, w^{0}, x_{i}^{1}, y_{i}^{1} ; \alpha\right)}{\mathrm{AE}^{0}\left(p^{0}, w^{0}, x_{i}^{0}, y_{i}^{0} ; \alpha\right)}=\hat{\mathrm{M}}^{0}\left(x_{i}^{0}, y_{i}^{0}, x_{i}^{1}, y_{i}^{1} ; \alpha\right) \cdot \mathrm{A}^{0}\left(p^{0}, w^{0}, x_{i}^{0}, y_{i}^{0}, x_{i}^{1}, y_{i}^{1} ; \alpha\right)
\end{aligned}
$$

By using the input and output prices as aggregating functions, the Laspeyres index yields a value which combines technical and economic criteria, and the duality between the return to dollar function and the generalized distance function -summarized in (11) and (12)- shows that these criteria can be identified by way of (22). Therefore, the Laspeyres index can be consistently decomposed into two mutually exclusive terms represented by a "real" component corresponding to the Malmquist productivity index defined on the benchmark optimal scale frontier, and an economic component representing the change in allocative performance of the evaluated process with respect to the base period. Values of the Laspeyres index greater, equal and lower than one respectively reflect productivity increases, stagnation or declines between the base and the comparison period. Similar reasoning can be applied to the Malmquist index from a technological perspective. With regard to the allocative term, values greater than one reflect that when $i$ changes its production process from the base to the comparison period, its projection on the base period frontier gets closer to the return to dollar maximizing input-output vector -represented by process $j$ in our case. If the allocative term is smaller than one, then the opposite takes place and the process gets farther away from the return to dollar maximizing vector. If it is equal to one, the relative distance of the production process to maximum return to dollar remains the same. In this case it is worth noting that if the base and comparison process is return to dollar efficient with respect to the base period, the Laspeyres index is equivalent to the base 
period Malmquist productivity index; i.e. a result that is obtained assuming constant returns to scale, return to dollar profitability maximization and allocative efficiency.

If instead of using the base period as benchmark for the analysis, one employs the comparison period, it is possible to obtain an analogous relationship between the Paasche productivity index and its comparison period Malmquist index, which is interpreted in the same way as (22). However, as the choice of performing the analysis using the base or the comparison period is arbitrary, it is possible to consider the geometric mean of the Laspeyres and Paasche productivity indexes. In this case, we can determine the exiting relationship between the Fisher index and the geometric mean of the base and comparison period Malmquist productivity indexes:

$$
\begin{aligned}
Q_{F} & =\left[Q_{L} Q_{P}\right]^{1 / 2}=\left[\frac{Q^{0,1}}{Q^{0,0}} \frac{Q^{1,1}}{Q^{1,0}}\right]^{1 / 2}=\left[\frac{p^{0} y_{i}^{1} / w^{0} x_{i}^{1}}{p^{0} y_{i}^{0} / w^{0} x_{i}^{0}} \frac{p^{1} y_{i}^{1} / w^{1} x_{i}^{1}}{p^{1} y_{i}^{0} / w^{1} x_{i}^{0}}\right]^{1 / 2}= \\
& =\left[\frac{\hat{\mathrm{D}}_{\mathrm{G}}^{0}\left(x_{i}^{1}, y_{i}^{1} ; \alpha\right)}{\hat{\mathrm{D}}_{\mathrm{G}}^{0}\left(x_{i}^{0}, y_{i}^{0} ; \alpha\right)} \frac{\hat{\mathrm{D}}_{\mathrm{G}}^{1}\left(x_{i}^{1}, y_{i}^{1} ; \alpha\right)}{\hat{\mathrm{D}}_{\mathrm{G}}^{1}\left(x_{i}^{0}, y_{i}^{0} ; \alpha\right)}\right]^{1 / 2} \cdot\left[\frac{\mathrm{A}^{0}\left(p^{0}, w^{0}, x_{i}^{1}, y_{i}^{1} ; \alpha\right)}{\mathrm{AE}^{0}\left(p^{0}, w^{0}, x_{i}^{0}, y_{i}^{0} ; \alpha\right)} \frac{\mathrm{AE}^{1}\left(p^{1}, w^{1}, x_{i}^{1}, y_{i}^{1} ; \alpha\right)}{\mathrm{A}^{1}\left(p^{1}, w^{1}, x_{i}^{0}, y_{i}^{0} ; \alpha\right)}\right]^{1 / 2}= \\
& =\hat{\mathrm{M}}^{0,1}\left(x_{i}^{0}, y_{i}^{0}, x_{i}^{1}, y_{i}^{1} ; \alpha\right) \cdot \mathrm{A}^{0,1}\left(p^{0}, w^{0}, p^{1}, w^{1}, x_{i}^{0}, y_{i}^{0}, x_{i}^{1}, y_{i}^{1} ; \alpha\right),
\end{aligned}
$$

As its Laspeyres and Paasche counterparts, the Fisher productivity index can be consistently decomposed into a technical term represented by the geometric mean of two Malmquist productivity indexes and an economic term reflecting the geometric mean of the change in allocative performance with respect to each benchmark period. Different productivity patterns for the Laspeyres, Paasche and Fisher indexes involving their corresponding technological and allocative components are illustrated with an example data set in section 7 .

Finally, we can extend the discussion on (23) focusing on the technical part of the Fisher index. With regard to the Malmquist productivity index, it is possible to rely on the extensive Malmquist decomposition literature initiated by Färe et al. (1994) and continued by Ray and Desli (1997) to identify the relevant sources of productivity change. The simplest way to decompose the Malmquist productivity index $\hat{\mathrm{M}}^{0,1}\left(x_{i}^{0}, y_{i}^{0}, x_{i}^{1}, y_{i}^{1} ; \alpha\right)$ is 


$$
\begin{aligned}
\hat{\mathrm{M}}^{0,1}\left(x_{i}^{0}, y_{i}^{0}, x_{i}^{1}, y_{i}^{1} ; \alpha\right)= & {\left[\frac{\mathrm{D}_{\mathrm{G}}^{0}\left(x_{i}^{0}, y_{i}^{0} ; \alpha\right)}{\mathrm{D}_{\mathrm{G}}^{1}\left(x_{i}^{0}, y_{i}^{0} ; \alpha\right)} \frac{\mathrm{D}_{\mathrm{G}}^{0}\left(x_{i}^{1}, y_{i}^{1} ; \alpha\right)}{\mathrm{D}_{\mathrm{G}}^{1}\left(x_{i}^{1}, y_{i}^{1} ; \alpha\right)}\right]^{1 / 2} \cdot \frac{\mathrm{D}_{\mathrm{G}}^{1}\left(x_{i}^{1}, y_{i}^{1} ; \alpha\right)}{\mathrm{D}_{\mathrm{G}}^{0}\left(x_{i}^{0}, y_{i}^{0} ; \alpha\right)} \cdot } \\
& \cdot\left[\frac{\hat{\mathrm{D}}_{\mathrm{G}}^{0}\left(x_{i}^{1}, y_{i}^{1} ; \alpha\right) / \mathrm{D}_{\mathrm{G}}^{0}\left(x_{i}^{1}, y_{i}^{1} ; \alpha\right)}{\hat{\mathrm{D}}_{\mathrm{G}}^{0}\left(x_{i}^{0}, y_{i}^{0} ; \alpha\right) / \mathrm{D}_{\mathrm{G}}^{0}\left(x_{i}^{0}, y_{i}^{0} ; \alpha\right)} \cdot \frac{\hat{\mathrm{D}}_{\mathrm{G}}^{1}\left(x_{i}^{1}, y_{i}^{1} ; \alpha\right) / \mathrm{D}_{\mathrm{G}}^{1}\left(x_{i}^{1}, y_{i}^{1} ; \alpha\right)}{\hat{\mathrm{D}}_{\mathrm{G}}^{1}\left(x_{i}^{0}, y_{i}^{0} ; \alpha\right) / \mathrm{D}_{\mathrm{G}}^{1}\left(x_{i}^{0}, y_{i}^{0} ; \alpha\right)}\right]^{1 / 2} .
\end{aligned}
$$

The first factor in the right hand side of this expresion captures the change in the best practice production frontiers evaluated at $\left(x_{i}^{0}, y_{i}{ }^{0}\right)$ and $\left(x_{i}{ }^{1}, y_{i}{ }^{1}\right)$, i.e. technical change. The second term captures the change in technical efficiency -previously discussed in (28). Finally, the third term can be interpreted as the contribution that returns to scale make to productivity change -in this we follow the evidence posed by Grifell-Tatjé and Lovell (1999), Orea (2002) and Lovell (2003) $)^{8}$. Substituting (24) into (23) yields

$$
\begin{aligned}
Q_{F}= & \mathrm{TC}^{0,1}\left(x_{i}^{0}, y_{i}^{0}, x_{i}^{1}, y_{i}^{1}\right) \cdot \mathrm{TEC}^{0,1}\left(x_{i}^{0}, y_{i}^{0}, x_{i}^{1}, y_{i}^{1}\right) \cdot \\
& \cdot \operatorname{RTS}^{0,1}\left(x_{i}^{0}, y_{i}^{0}, x_{i}^{1}, y_{i}^{1}\right) \cdot \mathrm{A}^{0,1}\left(p^{0}, w^{0}, p^{1}, w^{1}, x_{i}^{0}, y_{i}^{0}, x_{i}^{1}, y_{i}^{1}\right)
\end{aligned}
$$

This expression constitutes the extended decomposition of the Fisher productivity index. When interpreting the Fisher index as a change in return to dollar ratios, it can be decomposed into a technical component -consisting of technical change, technical efficiency change and returns to scale- and an economic component reflecting the contribution of allocative criteria to productivity change.

\section{Empirical Implementation by Means of the Activity Analysis}

In this section we illustrate how to undertake the efficiency and productivity analyses that lead to the extended decomposition of the Fisher productivity index. In doing so we have decided to continue with the activity analysis approach discussed by GeorgescuRoegen (1951), which can be empirically implemented by means of Data Envelopment Analysis, DEA, techniques. This approach to efficiency and productivity measurement

\footnotetext{
${ }^{8}$ Ray and Desli (1997) and Balk (2001) decided to name this last terms scale efficiency change. Nevertheless we believe that this description should be reserved to $\mathrm{SEC}^{0,1}$ as defined in (20) since, by comparing own period data and technologies, it is consistent with the structure of its counterpart technical efficiency change term $\mathrm{TEC}^{0,1}$-the only Malmquist productivity definition that has remained unchallenged since it was introduced by
} 
approximates the true but unknown technology by means of piecewise linear combinations of the observed data, which constitute a multidimensional production frontier -see Cooper, Seiford and Tone (2000) for an introduction to DEA within a production theory context. The DEA piecewise linear approximation of the technology (1) -including its constant returns to scale characterization, is given by

$$
\hat{\mathrm{T}}^{t}=\left\{(x, y): \sum_{i=1}^{\mathrm{I}} \mathrm{z}_{i}^{t} \mathrm{x}_{i n}^{t} \leq \mathrm{x}_{n}^{t}, n=1, \ldots, \mathrm{N} ; \sum_{i=1}^{\mathrm{I}} \mathrm{z}_{i}^{t} \mathrm{y}_{i m}^{t} \geq \mathrm{y}_{m}^{t}, m=1, \ldots, \mathrm{M} ; \mathrm{z}^{t} \in \mathfrak{R}_{+}^{\mathrm{I}}, i=1, \ldots, \mathrm{I}\right\}
$$

where $z^{t}$ is a intensity vector whose values determine the linear combinations of facets which define the production frontier.

Our first program deals with the empirical implementation of the overall return to dollar efficiency measure corresponding to (14). Specifically, to calculate this economic performance measure for any process (activity) $i$ ' we must solve the following linear programming problem:

$$
\begin{array}{ll} 
& \frac{p^{t} y_{i^{\prime}}^{t} / w^{t} x_{i^{\prime}}^{t}}{\rho\left(p^{t}, w^{t}\right)}=\min _{\omega, z_{i}^{t}, x_{n}^{t}, y_{m}^{t}} \omega \\
\text { s.t. } \quad & \sum_{i=1}^{\mathrm{I}} \mathrm{z}_{i}^{t} \mathrm{x}_{i n}^{t}=\mathrm{x}_{n}^{t}, n=1, \ldots, \mathrm{N}, \\
& \sum_{i=1}^{\mathrm{I}} \mathrm{z}_{i}^{t} \mathrm{y}_{i m}^{t}=\mathrm{y}_{m}^{t}, m=1, \ldots, \mathrm{M}, \\
& \sum_{i=i}^{\mathrm{I}} z_{i}^{t} \frac{w^{t} x_{i}^{t}}{p^{t} y_{i}^{t}}=\omega \frac{w^{t} x_{i^{\prime}}^{t}}{p^{t} y_{i^{\prime}}^{t}} \\
& \sum_{i=1}^{\mathrm{I}} \mathrm{z}_{i}^{t}=1, \quad z^{t} \in \mathfrak{R}_{+}^{\mathrm{I}} .
\end{array}
$$

As shown in section 4, this measure can be decomposed into a technical efficiency term represented by the generalized distance function $\hat{\mathrm{D}}_{\mathrm{G}}^{t}\left(x^{t}, y^{t} ; \alpha\right)$-comprising technical efficiency represented by $\mathrm{D}_{\mathrm{G}}^{t}\left(x^{t}, y^{t} ; \alpha\right)$ and scale efficiency (the ratio of the former to the latter) - and a residual allocative efficiency component. Therefore, to accomplish the return to dollar efficiency decomposition we need to calculate the generalized distance functions

Färe et al. (1994). For a thoughtful discussion of the alternative Malmquist productivity index decomposition see Zofío (2004). 
for i'. Extending the formulations discussed in Zofío and Lovell (2001) on how to calculate hyperbolic distance functions by means of non linear programming techniques, one can obtain the generalized function defined on the constant return to scale technology solving for

$$
\hat{\mathrm{D}}_{\mathrm{G}}^{t}\left(x_{i^{\prime}}^{t}, y_{i^{\prime}}^{t} ; \alpha\right)=\min _{\delta, z^{t}}\left\{\delta:\left(x_{i^{t}}^{t} \delta^{1-\alpha}, y_{i^{\prime}}^{t} / \delta^{\alpha}\right) \in \hat{\mathrm{T}}^{t}\right\}
$$

s.t.

$$
\begin{aligned}
& \sum_{i=1}^{\mathrm{I}} \mathrm{z}_{i}^{t} \mathrm{x}_{i n} \leq x_{i^{\prime} n}^{t} \delta^{1-\alpha}, \quad n=1, \ldots, \mathrm{N}, \\
& \sum_{i=1}^{\mathrm{I}} \mathrm{z}_{i}^{t} \mathrm{y}_{i m} \geq \mathrm{y}_{i^{\prime} m}^{t} / \delta^{\alpha}, \quad m=1, \ldots, \mathrm{M}, \\
& \mathrm{z}^{t} \in \mathfrak{R}_{+}^{\mathrm{I}},
\end{aligned}
$$

while the variable returns to scale generalized distance function $\mathrm{D}_{\mathrm{G}}^{t}(x, y ; \alpha)$ can be calculated solving for the same problem but adding the convexity constraint $\Sigma_{i=1}^{\mathrm{I}} \mathrm{Z}_{i}^{t}=1$. Finally, the allocative efficiency residual is the result of dividing the solution obtained when solving (27) by that of (28).

We can now extend the analysis to evaluate productivity change. To do so we must modify the DEA techniques to allow for mix-period optimizing programs as the ones required to calculate the Laspeyres and Fisher indexes (22) and (23). Starting with the overall return to dollar measure of the $i$ ' process in the comparison period with respect to the base period (21), it can be calculated solving for

$$
\begin{array}{ll}
\frac{p^{0} y_{i^{\prime}}^{1} / w^{0} x_{i^{\prime}}^{1}}{\rho\left(p^{0}, w^{0}\right)}=\min _{\omega, z_{i}^{0}, x_{n}^{0}, y_{m}^{0}} \omega \\
\text { s.t. } \quad \sum_{i=1}^{\mathrm{I}} \mathrm{z}_{i}^{0} \mathrm{x}_{i n}^{0}=\mathrm{x}_{n}^{0}, n=1, \ldots, \mathrm{N}, \\
\quad \sum_{i=1}^{\mathrm{I}} \mathrm{z}_{i}^{0} \mathrm{y}_{i m}^{0}=\mathrm{y}_{m}^{0}, m=1, \ldots, \mathrm{M}, \\
\quad \sum_{i=i}^{\mathrm{I}} z^{0} \frac{w^{0} x_{i}^{0}}{p^{0} y_{i}^{0}}=\omega \frac{w^{0} x_{i^{\prime}}^{1}}{p^{0} y_{i^{\prime}}^{1}}, \\
\sum_{i=1}^{\mathrm{I}} \mathrm{z}_{i}^{0}=1, \quad \mathrm{z}^{0} \in \mathfrak{R}_{+}^{\mathrm{I}},
\end{array}
$$


which can be easily modified to calculate the equivalent return dollar measure of the same process observed in the base period process and using the comparison period as benchmark, i.e. $\left(p^{1} y_{i^{\prime}}^{0} / w^{1} x_{i^{\prime}}^{0}\right) / \rho\left(p^{1}, w^{1}\right)$-as would be required by the Paasche and Fisher indexes. Also the mix-period generalized productive efficiency of process $i$ ' observed in the comparison period with respect to the base period technology can be obtained by modifying (21) and solving for:

$\hat{\mathrm{D}}_{\mathrm{G}}^{0}\left(x_{i^{\prime}}^{1}, y_{i^{\prime}}^{1} ; \alpha\right)=\min _{\delta, z_{i}^{0}}\left\{\delta:\left(x_{i^{\prime}}^{1} \delta^{1-\alpha}, y_{i^{\prime}}^{1} / \delta^{\alpha}\right) \in \hat{\mathrm{T}}^{0}\right\}$

s.t.

$\sum_{i=1}^{\mathrm{I}} \mathrm{z}_{i}^{0} \mathrm{x}_{i n}^{0} \leq x_{i^{\prime} n}^{1} \delta^{1-\alpha}, \quad n=1, \ldots, \mathrm{N}$

$\sum_{i=1}^{\mathrm{I}} \mathrm{z}_{i}^{0} \mathrm{y}_{i m}^{0} \geq \mathrm{y}_{i^{\prime} m}^{1} / \delta^{\alpha}, \quad m=1, \ldots, \mathrm{M}$,

$Z^{0} \in \mathfrak{R}_{+}^{\mathrm{I}}$,

while its mix-period counterpart $\hat{\mathrm{D}}_{\mathrm{G}}^{1}\left(x_{i^{\prime}}^{0}, y_{i^{\prime}}^{0} ; \alpha\right)$ requires to reverse all time superscripts in the objective function and the $\mathrm{N}$ plus $\mathrm{M}$ restrictions. As with (28) to calculate the variable returns to scale generalized functions representing mix period technical efficiencies $\mathrm{D}_{\mathrm{G}}^{1}\left(x_{i^{\prime}}^{0}, y_{i^{\prime}}^{0} ; \alpha\right)$ and $\mathrm{D}_{\mathrm{G}}^{0}\left(x_{i^{\prime}}^{1}, y_{i^{\prime}}^{1} ; \alpha\right)$ it is necessary to solve the same problems adding $\Sigma_{i=1}^{\mathrm{I}} \mathrm{Z}_{i}^{t}=1$.

All these programs allow the empirical implementation of the proposed efficiency and productivity change analysis, rendering possible to decompose the familiar Laspeyres, Paasche and Fisher indexes into technical and economic components.

\section{An illustrating example}

To illustrate the efficiency and productivity change model we consider a panel of five processes observed in the base and the comparison period. Table 1 presents the alternative input-output vectors and their corresponding prices in $t=0$ and $t=1$. In this particular example we have chosen $\alpha=0.5$ which yields a balanced generalized function that proportionally increases outputs and reduces inputs in the same proportion. Notice that according to $\mathrm{D}_{\mathrm{G}} 4$ a different choice of $\alpha$ would only affect the extended decomposition of 
the Malmquist productivity indexes (24) but not the Malmquist and allocative indexes comprised in the Fisher index (23).

An examination of the example data set reveals that processes 2 and 3 dominate all other processes from a technical perspective in both periods, defining the envelopment frontier, -i.e. their technical efficiency scores in the base and the comparison periods are equal to one, see Table 2. Nevertheless, from an economic perspective, while the second process is return to dollar efficient in the base period, it is the third process the one to become return to dollar efficient in the comparison period. This outcome derives from the fact that comparing both processes in the first period, the second process produces a larger amount of the more expensive output while employing a larger amount of the cheaper input, while this situation reverses in the comparison period. As a result, Table 2 shows that the third process increases its return to dollar efficiency by $30.7 \%$, while the second process endures an efficiency loss of $-9 \%$-both coming from allocative efficiency change.

With regard to the first and the fifth processes, both are productive inefficient in the base and the comparison period. They do not define the best practice variable returns to scale efficient frontiers and their technical efficiency scores are less than one. Also, as their efficient projections on the best practice production frontiers do not constitute benchmark optimal scales, their scale efficiency is also lower than one. This defective performance yields a high degree of productive inefficiency. Furthermore, once projected to the benchmark optimal scale frontier solving technical and scale inefficiencies, their projected processes do not belong to the maximizing return to dollar hyperplanes, and therefore they are allocative inefficient with associated scores smaller than one. From a return to dollar efficiency change perspective, while the first process endures growing return to dollar inefficiency by $30.0 \%$, the latter increases its return to dollar efficiency by $82.9 \%$. The reason is that the first process gets farther away from the best practice and benchmark optimal scale frontiers from the base to the comparison period. It also losses allocative inefficiency by showing an input-output mix which also diverges from the return to dollar maximizing vector represented by the third process in the comparison period. The opposite situation is experienced by the fifth process that gains both technical, scale and allocative efficiency by getting closer to the best practice and benchmark optimal scale production frontiers, while also getting closer to the input-output mix which maximizes return to dollar in the comparison period. 
Finally, the fourth process illustrates the case of simultaneous scale and allocative efficiency. Its values correspond to the following projection of the overall efficient second process: $\left(x_{4}{ }^{t}, y_{4}{ }^{t}\right)=\left(4^{0.5} x_{2}{ }^{t}, y_{2}{ }^{t} / 4^{0.5}\right)$ and by (11) it is also scale and allocative efficient in the base period. That is, once it has been projected to the best practice frontier by an amount equal to $\mathrm{D}_{\mathrm{G}}^{0}\left(x_{4}^{0}, y_{4}^{0} ; 0.5\right)=0.25$, which happens to be the benchmark optimal scale corresponding to the second process, it also belongs to the maximizing return to dollar hyperplane.

We now proceed to evaluate productivity change and the alternative Laspeyres, Paasche and Fisher decompositions. Table 3 shows how these indexes yield productivity gains for all processes but the first one. Focusing on the Fisher index results, the first process experiences a productivity decline of $-18.6 \%$. The decomposition of this productivity loss using equation (23) shows that it mainly comes from a worsening technical situation as its Malmquist index shows decreasing productivity by an amount of $20.1 \%$. On the contrary, this process improves its situation from an allocative perspective, which nevertheless barely counterbalances technical productivity loss by $1.9 \%$. We can gain insight into the technical productivity loss of $-20.1 \%$ by means of equation (24). Clearly, the main source for this loss is a worsening situation due to the frontier downward shift at its output-input scales by $31.9 \%$, followed by a $-1.8 \%$ technical inefficiency growth. Nevertheless, the output and input scale change with regard to the most productive scale sizes in both periods brings along increasing returns by an amount of $19,4 \%$, which partially compensates the other two sources of productivity decline. The largest productivity gain corresponds to the fifth process, which presents a Fisher productivity index increase of $82.8 \%$. From a technological perspective, its Malmquist productivity index shows a productivity gain up to $68.5 \%$, which is complemented with a better allocative performance which results in a productivity increase equivalent to $8.5 \%$. With regard to the Malmquist index, this process shows technical progress by $65.5 \%$, while enjoying technical efficiency gains by $11.8 \%$ but decreasing returns to scale up to $-8.9 \%$. 
Table 1. Example Data Set

\begin{tabular}{c|cccc|c|cccc|c} 
Process & $\mathrm{y}_{1}{ }^{0}$ & $\mathrm{y}_{2}{ }^{0}$ & $\mathrm{x}_{1}{ }^{0}$ & $\mathrm{x}_{2}{ }^{0}$ & & $\mathrm{y}_{1}{ }^{1}$ & $\mathrm{y}_{2}{ }^{1}$ & $\mathrm{x}_{1}{ }^{1}$ & $\mathrm{x}_{2}{ }^{1}$ & \\
\hline 1 & 7 & 4 & 5 & 3 & $\mathrm{p}_{1}{ }^{0}=3$ & 18 & 10 & 14 & 12 & $\mathrm{p}_{1}{ }^{1}=3$ \\
2 & 10 & 8 & 2 & 4 & $\mathrm{p}_{2}{ }^{0}=2$ & 36 & 28 & 8 & 10 & $\mathrm{p}_{2}{ }^{1}=5$ \\
3 & 8 & 10 & 4 & 2 & $\mathrm{w}_{1}{ }^{0}=2$ & 28 & 36 & 10 & 8 & $\mathrm{w}_{1}{ }^{1}=3$ \\
4 & 5 & 4 & 4 & 8 & $\mathrm{w}_{2}{ }^{0}=1$ & 18 & 14 & 16 & 20 & $\mathrm{w}_{2}{ }^{1}=4$ \\
5 & 3 & 6 & 7 & 9 & & 12 & 20 & 14 & 17 & \\
\hline
\end{tabular}

Table 2. Return to Dollar Efficiency (14) and Return to Dollar Efficiency Change (20).

\begin{tabular}{|c|c|c|c|c|c|c|c|c|c|c|c|c|c|c|c|}
\hline Process & $\mathrm{RDE}^{0}$ & $\mathrm{PE}^{0}$ & $\mathrm{TE}^{0}$ & $\mathrm{SE}^{0}$ & $\mathrm{AE}^{0}$ & $\mathrm{RDE}^{1}$ & $\mathrm{PE}^{0}$ & $\mathrm{TE}^{1}$ & $\mathrm{SE}^{1}$ & $\mathrm{AE}^{1}$ & $\mathrm{RDEC}^{0,1}$ & $\mathrm{PEC}^{0}$ & $\mathrm{TEC}^{0,1}$ & $\mathrm{SEC}^{0,1}$ & $\mathrm{AEC}^{0,}$ \\
\hline 1 & 0.388 & 0.636 & 0.682 & 0.933 & 0.610 & 0.271 & 0.556 & 0.669 & 0.830 & 0.488 & 0.700 & 0.873 & 0.982 & 0.889 & 0.801 \\
\hline 2 & 1.000 & 1.000 & 1.000 & 1.000 & 1.000 & 0.910 & 1.000 & 1.000 & 1.000 & 0.910 & 0.910 & 1.000 & 1.000 & 1.000 & 0.910 \\
\hline 3 & 0.765 & 1.000 & 1.000 & 1.000 & 0.765 & 1.000 & 1.000 & 1.000 & 1.000 & 1.000 & 1.307 & 1.000 & 1.000 & 1.000 & 1.307 \\
\hline 4 & 0.250 & 0.250 & 0.250 & 1.000 & 1.000 & 0.228 & 0.250 & 0.250 & 1.000 & 0.910 & 0.910 & 1.000 & 1.000 & 1.000 & 0.910 \\
\hline 5 & 0.159 & 0.261 & 0.360 & 0.725 & 0.609 & 0.290 & 0.397 & 0.402 & 0.986 & 0.732 & 1.829 & 1.521 & 1.118 & 1.361 & 1.202 \\
\hline
\end{tabular}

Table 3. Laspeyres (22), Paasche and Fisher (23) Productivity Indexes Decompositions.

\begin{tabular}{c|ccc|ccc|ccc|ccc|} 
Process & $Q_{L}$ & $\hat{\mathrm{M}}^{0}$ & $\mathrm{~A}^{0}$ & $Q_{\mathrm{P}}$ & $\hat{\mathrm{M}}^{1}$ & $\mathrm{~A}^{1}$ & $Q_{\mathrm{F}}$ & $\hat{\mathrm{M}}^{0,1}$ & $\mathrm{~A}^{0,1}$ & $\mathrm{TC}^{0,1}$ & $\mathrm{TEC}^{0,1}$ & $\mathrm{RTS}^{0,1}$ \\
\hline 1 & 0.829 & 0.744 & 1.114 & 0.799 & 0.857 & 0.932 & 0.814 & 0.799 & 1.019 & 0.681 & 0.982 & 1.194 \\
2 & 1.097 & 1.286 & 0.853 & 1.218 & 0.877 & 1.389 & 1.156 & 1.062 & 1.089 & 0.900 & 1.000 & 1.180 \\
3 & 1.266 & 1.286 & 0.985 & 1.151 & 0.877 & 1.313 & 1.207 & 1.062 & 1.137 & 0.900 & 1.000 & 1.180 \\
4 & 1.097 & 1.286 & 0.853 & 1.218 & 0.877 & 1.389 & 1.156 & 1.062 & 1.089 & 0.900 & 1.000 & 1.180 \\
5 & 1.850 & 1.704 & 1.086 & 1.807 & 1.667 & 1.084 & 1.828 & 1.685 & 1.085 & 1.655 & 1.118 & 0.911 \\
\hline
\end{tabular}


Finally, it is possible to discuss how the technically efficient processes which operate at the most productive scale behave and the effect they have on the remaining processes. The second and third processes experience productivity gains larger in the latter than the former, i.e $20.7 \%$ as opposed to $15.6 \%$. It is interesting to note that their Malmquist productivity indexes reach the same value of 1.062. This result illustrates how they define equivalent benchmark productive frontiers in both periods -or facets in DEA terminology- when estimating the intertemporal or mix-period distance functions as defined right after equation (21) and developed in (30). With regard to the fourth process, it also projects onto the same hyperplane, as it is a simple downward rescalation of the second process. However, even if for the same reason they all share the same technical change $-10.0 \%$, technical efficiency change $0.0 \%$, and returns to scale $18.0 \%$, their allocative situation is not the same. In fact, while the improving allocative performance of the third process results in a productivity increase of $13.7 \%$, the second and fourth processes experience a productivity gain of just $8.9 \%$, which is responsible for their aggregate Fisher productivity differential. It is worth remarking that these processes lead the change in the most productive scale sizes into an area of increasing returns which is followed by the first and fourth process but not by the fifth process -it expands to an alternative scale that bears decreasing returns to scale. Nevertheless its technical and efficiency change geometric means signal that by changing its production process to such extent, it is able to take advantage of technical progress, while the leading firms do not experience these gains.

\section{Conclusions}

This article presents the equivalence between the widely applied Laspeyres, Paasche and Fisher productivity indexes and their associated Malmquist productivity indexes, by way of the existing duality between the return to dollar function and the generalized graph distance function. By relying on this duality, we have shown how it is possible to undertake static and dynamic Farrell efficiency and productivity measurement and how to allocate efficiency and productivity change between two mutually exclusive technical and economic components. Specifically, when allowing for allocative criteria, it is shown how the Laspeyres, Paasche and Fisher indexes can be decomposed into Malmquist technical indexes and allocative indexes. With regard to the Fisher index, it is possible to recall the 
existing literature on Malmquist productivity indexes decompositions to identify the relevant sources of productivity change, i.e. technical change, technical efficiency change and returns to scale.

As the Fisher productivity index is standard practice for statistical offices, and the proposed decomposition of the Malmquist index is by now a routine exercise in applied analysis -though not exempt of controversy as summarized by Balk (2001) and Lovell (2003), we believe that while implementation of the model would require a limited amount of time and resources, the insight that is gained into the sources of productivity change is remarkable -as it unveils the technology underlying the Fisher index and the effect of prices on the allocative performance of the production processes.

To reinforce our call for the empirical implementation of the model we have developed the DEA techniques necessary to calculate return to dollar efficiency and the generalized graph distance functions. Also, we have shown how to modify these mathematical programs as to allow for intertemporal or mix-period measures, which are in turn necessary to decompose the Laspeyres, Paasche and Fisher indexes into Malmquist and allocative indexes. Finally, using an example data set, we illustrate the potential of the model for efficiency and productivity analysis, as well as the applicability of the DEA programs we have introduced. 


\section{References}

Abramovitz, M. (1956) Resource and Output Trends in the United States Since 1870. National Bureau of Economic Research Occassional Paper 52.

Althin, R., R. Färe and S. Grosskopf (1996) "Profitability and Productivity Change: An Application to Swedish Pharmacies," Annals of Operations Research 66: 219-233.

Balk, B. (1998) Industrial Price, Quantity and Productivity Indexes: The Microeconomic Theory and An Application. Boston: Kluwer Academic Publishers.

Balk, B. (2001) "Scale Efficiency and Productivity Change," Journal of Productivity Analysis 15: $153-183$.

Chambers, R., Y. Chung and R. Färe (1998), "Profit, Directional Distance Functions and Nerlovian Efficiency,” Journal of Optimization Theory and Applications, 95 (2): 351364.

Chavas, J-P. and T.M. Cox (1999), "A Generalized Distance Function and the Analysis of Production Efficiency,” Southern Economic Journal, 66(2): 295-318.

Cooper, W., L. Seiford L. and K. Tone (2000), Data Envelopment Analysis, A Comprehensive Text with Models, Applications, References and DEA-Software. Boston: Kluwer Academic Publishers.

Diewert, E.W. (1992), "The Measurement of Productivity,” Bulletin of Economic Research, 44 (3): 163-198.

Diewert, E. W. and D. Lawrence (1999), Measuring New Zealand's Productivity, Treasury Working Paper 99/5, http://www.treasury.govt.nz/workingpapers/99-5.htm.

Färe, R. and S. Grosskopf (2000), "Notes on Some Inequalities in Economics," Economic Theory, 15 (1): 227-33

Färe, R., S. Grosskopf, B. Lindgren and P. Roos (1994), "Productivity Developments in Swedish Hospitals: A Malmquist Output Approach,” In: Charnes, A., W. Cooper, A. Lewin and L. Seiford (eds.), Data Envelopment Analysis: Theory, Methodology and Applications. Dordrecht: Kluwer Academic Publishers.

Färe, R., S. Grosskopf and C.A.K. Lovell (1985), The Measurement of Efficiency of Production. Boston: Kluwer Nijhoff Publishing.

Färe, R., S. Grosskopf S. and T. Zaim (2002) "Hyperbolic Efficiency and Return to Dollar. European Journal of Operational Research,” 136: 671-679.

Färe, R. and D. Primont (1995), Multi-output Production and Duality: Theory and Applications. Dordrecht: Kluwer Academic Publishers. 
Farrell, M. (1957), "The Measurement of Productive Efficiency," Journal of the Royal Statistical Society. Series A, General, 120 (3): 253-281.

Fisher, I. (1921), “The Best Form of Index Number," Journal of the American Statistical Association, 17: 533-537.

Georgescu-Roegen, N. (1951), "The Aggregate Linear Production Function and its Application to Von Newman's Economic Model.” In: T. Koopmans (ed.) Activity Analysis of Production and Allocation. Wiley, New York.

Grifell-Tatjé, E. and C.A.K. Lovell (1999), "A Generalized Malmquist Productivity Index," Trabajos en Investigación Operativa, Top, 7 (1): 81-101.

Griliches, Z. (1987), "Productivity: Measurement Problems,” In: J. Eatwell, M. Milgate and P. Newman (eds.) The New Palgrave: A Dictionary of Economics. New York: Palgrave Macmillan.

Harberger, A. C. (1998), "A Vision of the Growth Process," American Economic Review, 88 (1): $1-32$

Laspeyres, E. (1871), “Die Berechnung einer mittlerer Waarenpreissteigerung,” Järbucher für Nationalokönomie und Stististik, 16: 296-314.

Lovell, C.A.K. (2003), “The Decomposition of Malmquist Productivity Indexes,” Journal of Productivity Analysis. 20: 437-438.

Malmquist, S. (1953), "Index Numbers and Indifference Curves," Trabajos de Estadística, 4 (1): 209-242.

McFadden, D. (1978), "Cost, Revenue, and Profit Functions," In: Fuss, M. and D. McFadden (eds.), Production Economics: A Dual Approach to Theory and Applications. North-Holland, Amsterdam.

OECD (2001), Measuring Productivity. Measurement of Aggregate and Industry Level Productivity Growth. Paris: Organization for Economic Co-operation and Development.

Orea, L. (2002), "Parametric Decomposition of a Generalized Malmquist Productivity Index," Journal of Productivity Analysis, 18: 5-22.

Paasche, H. (1874), "Uber die Preisentwicklung der Letzen Jahre Nach den Hamburger Börsennotinrungen,” Järbucher für Nationalokönomie und Stististik, 23: 168-178.

Ray. S. and E. Desli (1997), "Productivity Growth, Technical Progress, and Efficiency Change in Industrialized Countries: Comment," American Economic Review, 87 (5): 1.033-1.039. 
Shephard, R. (1970), Theory of Cost and production Functions. New Jersey: Princeton University Press.

Törnqvist, L. (1936), “The Bank of Finland's Consumer Price Index,” Bank of Finland Monthly Bulletin, 19: 1-8.

Zofío, J.L. and C.A.K. Lovell (2001), "Graph Efficiency and Productivity Measures: An Application to U.S. Agriculture," Applied Economics, 33: 1433-1442.

Zofio, J.L. (2001), Malmquist Productivity Index Decompositions: A Unifying Framework. Departamento de Análisis Económico, Universidad Autónoma de Madrid, mimeo. 